\title{
Article
}

\section{Development of Four-Channel Buck-Type LED Driver with Automatic Current Sharing}

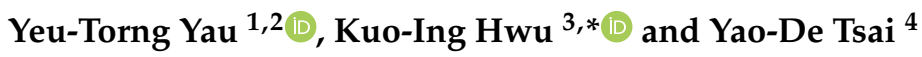 \\ 1 Department of Ph.D. Program, Prospective Technology of Electrical Engineering and Computer Science, \\ National Chin-Yi University of Technology, No. 57, Sec. 2, Zhongshan Road, Taiping District, \\ Taichung 41170, Taiwan; pabloyau@ncut.edu.tw \\ 2 Department of Electrical Engineering, National Chin-Yi University of Technology, No. 57, Sec. 2, \\ Zhongshan Road, Taiping District, Taichung 41170, Taiwan \\ 3 Department of Electrical Engineering, National Taipei University of Technology, No. 1, Sec. 3, \\ Zhongxiao East Road, Taipei 10608, Taiwan \\ 4 LITE-ON Technology Corporation, 22F. No. 392, Ruiguang Road, Neihu District, Taipei 11492, Taiwan; \\ Jimmy.YD.Tsai@liteon.com \\ * Correspondence: eaglehwu@ntut.edu.tw; Tel.: +886-2-27712171 (ext. 2159)
}

Citation: Yau, Y.-T.; Hwu, K.-I.; Tsai, Y.-D. Development of Four-Channel Buck-Type LED Driver with Automatic Current Sharing. Energies 2021, 14, 7844. https://doi.org/ $10.3390 /$ en14237844

Academic Editor: Mohamed Benbouzid

Received: 22 October 2021

Accepted: 20 November 2021

Published: 23 November 2021

Publisher's Note: MDPI stays neutral with regard to jurisdictional claims in published maps and institutional affiliations.

Copyright: (c) 2021 by the authors. Licensee MDPI, Basel, Switzerland. This article is an open access article distributed under the terms and conditions of the Creative Commons Attribution (CC BY) license (https:// creativecommons.org/licenses/by/ $4.0 /)$.

\begin{abstract}
A buck-type light-emitting diode (LED) driver is proposed herein. The proposed LED driver automatically possesses current sharing and high step-down voltage gain. Without complex control, the proposed LED driver, with a single input and multiple outputs, can achieve automatic current sharing of four-channel LED strings, even under the different number of LEDs of each LED string. Furthermore, as compared with the traditional four-phase interleaved buck converter with a single input and a single output having current sharing required, the proposed circuit has the duty cycle up to 0.5 , not 0.25 , meaning that under the same input voltage the latter has a wider output voltage range than that of the former. Above all, if the proposed circuit with $N$ outputs, then it still has the duty cycle up to 0.5 , not one over $N$ as shown traditionally. Moreover, as compared with the current sharing based on the differential-mode transformer, the proposed circuit has no magnetic resetting loop required. In this paper, the operating principles and design considerations of the proposed converter are discussed. Finally, the theoretical analyses and performances of the proposed LED driver are verified by simulation and experiment.
\end{abstract}

Keywords: capacitor; current sharing; differential-mode transformer; FPGA; LED driver; single input; multiple outputs

\section{Introduction}

With the progress of science and technology and economic development, traditional incandescent lamps and power-saving bulbs have been gradually replaced by light-emitting diodes (LEDs), because LEDs have the advantages of small size, long life, high efficiency of electricity, low pollution and rapid reaction, more in line with the needs of today's market $[1,2]$.

In general, LEDs will be connected first in series and then in parallel. This is because if only the series connection is used, the resulting voltage across the LED string will be relatively high, thereby causing the output capacitor to endure a high voltage stress. In addition, if one of the LEDs is burned out, then the whole series of LEDs cannot work. When connected in parallel, LEDs are necessary to have a function of current balance. This is because LEDs have negative temperature coefficient characteristics. If the currents in two LEDs paralleled are imbalanced, one of LED currents will gradually rise, resulting in shortening or even burning out this LED. Therefore, many studies have proposed LED current balance methods so as to make the currents evenly distributed among paralleled LED strings. 
The LED current balance is mainly divided into active and passive. The active method [3-7] makes the load current evenly distributed among phases or modules strings. The work in [3] shows a dimming LED driver based on single-input multi-output (SIMO) buck DC-DC converter. The authors in [4] display the current balance for an interleaved LLC resonant converter based on a hybrid rectifier which is utilized to compensate the voltage gain of each phase so as to achieve current balance between the two phases. The study in [5] employs inner loop current sharing and average current processing to balance the current between two modules. The authors in [6] utilize inner current sharing plus a fixed duty cycle not only to balance the currents between the two phases but also to reduce the output ripple. The authors in [7] employ variable inductors to achieve current balance. From the studies in [3-7], it can be seen that more current sensors and controllers are required, thereby making the corresponding circuit more complex and costly. Accordingly, the passive method is presented based on circuit features to achieve the current balance. This method can be classified into two types: differential-mode transformer [8-10] and capacitor [11-15]. Both types generally belong to the SIMO structure, different from single-input single-output (SISO). The former type needs demagnetizing loop, making the required circuit more complicated than the latter type. As compared with active current balance, these two types generally have structure extension and no current balance controller, relatively small size, and low cost. The first type is based on transformer behavior and its operating principle is that when the currents in two LED strings are unbalanced, the differential-mode transformer has the voltages across both sides, and then the differentialmode transformer is activated, thereby forcing the current balance between the two LED strings. The authors in [8] employ the Zeta converter as driving LED strings and recycling magnetizing energy of the differential-mode transformer. The study in [9] couples the two input inductors of the boost converter into the differential-mode transformer to render the current evenly distributed between two LED strings. In [10], both types are used to achieve current balance.

Regarding capacitive current balance, it is based on ampere-second balance, that is, the average current is zero over one period in the steady state. The work in [11] presents an LED driver with galvanic isolation and capacitive current balance. The authors in [12] present an LED with regenerative snubber and capacitive current balance, but the corresponding circuit has no structure extension. The study in [13] displays the non-isolated resonant LED driver with capacitive current balance, but the number of resonant components is increased if the number of outputs increased. The authors in [14] use resonant current balance module to realize capacitive current balance as well as zero-voltage-switching (ZVS) turn-on, but the number of resonant components and switches is increased if the number of outputs increased. The study in [15] utilizes the inherent features of the halfbridge series resonant converter to achieve capacitive current balance and dimming, but the current sharing error percentage is large. In addition, the experimental step-up voltage gains used in the studies [11-13] and the experimental step-down voltage gains used in $[14,15]$ are not so good.

On the other hand, ref. [16] presents the interleaved buck LED driver with automatic capacitive current balance and a suitable duty cycle needed to improve the step-down voltage gain. However, in this circuit, the input and output grounds are separated by the switches, thus restricting converter applications as well as complicating control design. Moreover, the phase counts cannot be changed. Consequently, [17] presents a circuit to conquer the demerits coming from the work in [16].

The authors in [17] propose a four-phase interleaved buck-type converter having high step-down voltage gain, as shown in Figure 1. Furthermore, such a circuit has automatic current balance under the condition that the maximum duty cycle is limited to 0.25 . The corresponding voltage gain in the continuous conduction mode (CCM) is 0.25. In [17], the four switches have the same duty cycle with phases of $0^{\circ}, 90^{\circ}, 180^{\circ}$ and $270^{\circ}$, respectively. The duty cycle is up to 0.25 if the current sharing is required. In the proposed circuit, the four switches also have the same duty cycle with phases of $0^{\circ}, 180^{\circ}, 0^{\circ}$ and $180^{\circ}$, 
respectively, and the duty cycle is up to 0.5 if the current sharing is required. Accordingly, under the same input voltage the latter has a wider output voltage range than that of the former. Above all, under automatic current sharing, the maximum duty cycle of the latter is relatively large and not changed for structure extension whereas the maximum duty cycle of the former will be reduced as the number of outputs is increased. In addition, the former is of SISO and the latter is of SIMO.

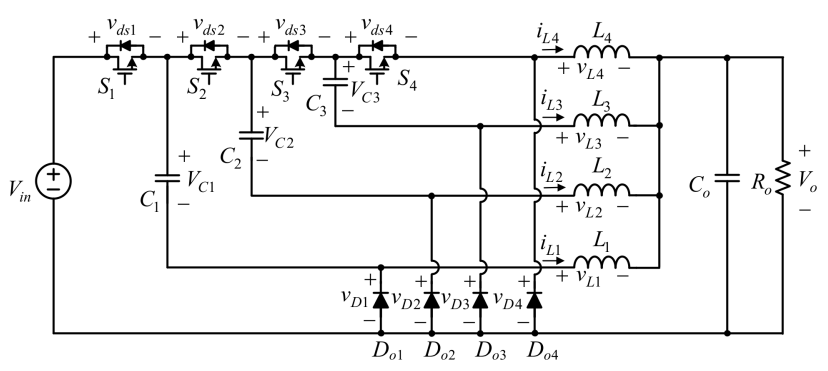

Figure 1. Circuit proposed by the study in [17].

In the following, there are four sections left. The first section will describe the proposed LED driver. The second section will talk about design considerations. The third section will give experimental results. The final section will make a conclusion.

\section{Proposed LED Driver}

The proposed LED driver with automatic current balance is displayed in Figure 2, derived from the circuit shown in [17], and constructed by four switches $S_{1}, S_{2}, S_{3}$ and $S_{4}$, four diodes $D_{1}, D_{2}, D_{3}$ and $D_{4}$, three energy-transferring capacitors $C_{1}, C_{2}$ and $C_{3}$, four output inductors $L_{1}, L_{2}, L_{3}$ and $L_{4}$, and four output capacitors $C_{01}, C_{02}, C_{03}$ and $C_{04}$. As for the load, it is built up by four LED strings $L S_{1}, L S_{2}, L S_{3}$ and $L S_{4}$. The four output inductors of the proposed LED driver, different from the circuit shown in [17], are connected to individual output capacitors and LED strings. Speaking lucidly, the proposed circuit is of SIMO, whereas the circuit shown in [17] is of SISO.

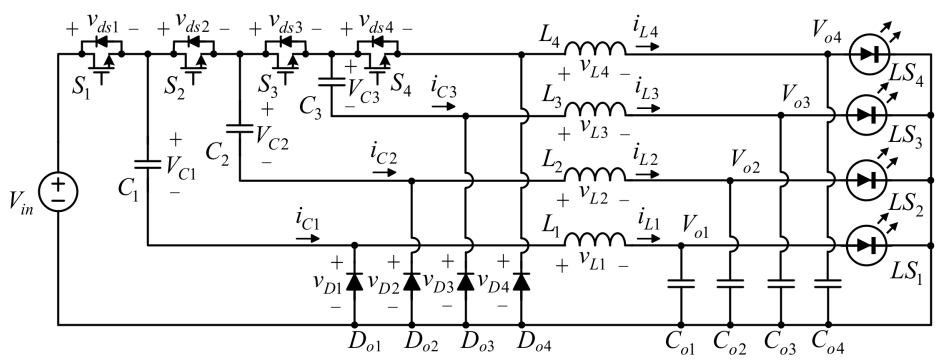

Figure 2. LED driver with automatic current sharing.

\subsection{Converter Operating in CCM}

Prior to proceeding with the circuit analysis, some related symbol definitions and required assumptions will be made as follows.

(1) The values of the energy-transferring capacitors $C_{1}, C_{2}, C_{3}$, and the output capacitors $C_{01}, C_{02}, C_{03}$ and $C_{04}$ are large enough, so the voltages across them are regarded as fixed values.

(2) $V_{\text {in }}$ is the input voltage, and $V_{o 1}, V_{o 2}, V_{o 3}$ and $V_{o 4}$ are the voltages across $L S_{1}, L S_{2}$, $L S_{3}$, and $L S_{4}$, respectively and they are identical, assuming that $V_{o 1}=V_{o 2}=V_{o 3}=V_{o 4}=V_{o}$. $L_{4}=L$.

(3) It is assumed that the values of the four inductors are equal, that is, $L_{1}=L_{2}=L_{3}=$

(4) $i_{L 1}, i_{L 2}, i_{L 3}$ and $i_{L 4}$ are the currents flowing through $L_{1}, L_{2}, L_{3}$ and $L_{4}$, respectively, and $i_{C 1}, i_{C 2}$ and $i_{C 3}$ are the currents flowing through $C_{1}, C_{2}$ and $C_{3}$, respectively. 
(5) $v_{L 1}, v_{L 2}, v_{L 3}$ and $v_{L 4}$ are the voltages across $L_{1}, L_{2}, L_{3}$ and $L_{4}$, respectively, $v_{d s 1}$, $v_{d s 2}, v_{d s 3}$ and $v_{d s 4}$ are the voltages across $S_{1}, S_{2}, S_{3}$ and $S_{4}$, respectively, $v_{D 1}, v_{D 2}, v_{D 3}$ and $v_{D 4}$ are the voltages across $D_{1}, D_{2}, D_{3}$ and $D_{4}$, respectively, and $V_{C 1}, V_{C 2}$ and $V_{C 3}$ are the voltages across $C_{1}, C_{2}$ and $C_{3}$, respectively.

(6) $T_{s}$ is the switching period and $f_{s}$ is the switching frequency, where $T_{s} \times f_{s}=1$.

(7) $D_{1} T_{s}, D_{2} T_{s}, D_{3} T_{s}$ and $D_{4} T_{s}$ are the conduction times of the switches $S_{1}, S_{2}, S_{3}$ and $S_{4}$, respectively. Assume that the four duty cycles are identical, that is, $D_{1}=D_{2}=D_{3}=D_{4}=D$. Since the four-phase currents must flow evenly, the duty cycle $D$ must be less than 0.5 .

(8) All the switches, diodes, inductors and capacitors in the circuit are regarded as ideal components, but the body diode connected to the switch is still considered. That is, the turn-on resistance of the switch, the forward voltage and parasitic resistance of the diode, and the parasitic resistance of the capacitor are ignored.

(9) $v_{g s 1}, v_{g s 2}, v_{g s 3}$ and $v_{g s 4}$ are the gate driving signals for the four switches $S_{1}, S_{2}, S_{3}$ and $S_{4}$, respectively.

(10) $v_{\text {dsi,statey }}$ means the voltage across the $i$-th switch during the y-th state, whereas $v_{D i \text {,statey }}$ means the voltage across the $i$-th diode during the $y$-th state.

(11) The circuit operates in the continuous conduction mode (CCM). There are four operating states over one switching cycle, as shown in Figure 3.

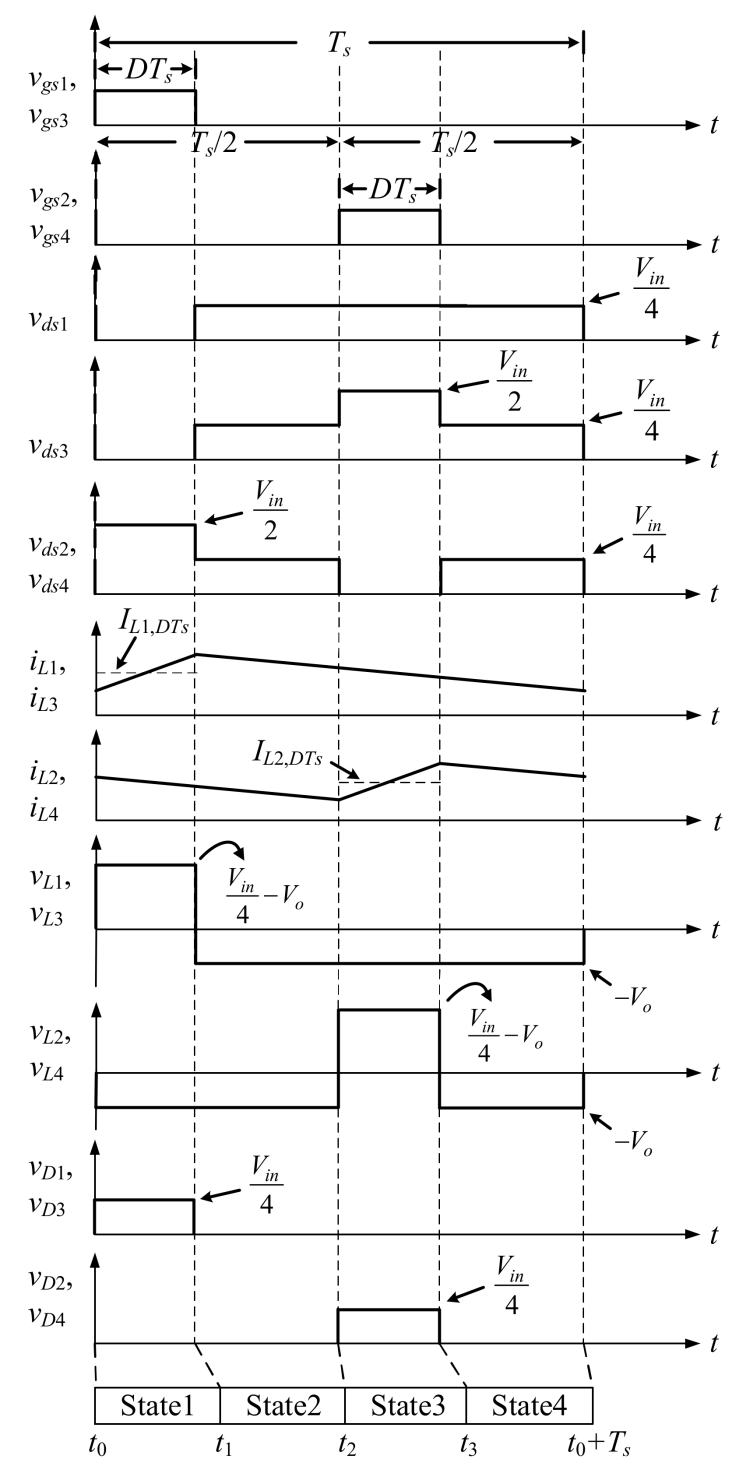

Figure 3. Waveforms relevant to the converter operating in CCM. 
State $1\left[t_{0} \leq t \leq t_{1}\right]$ : As shown in Figure 4 , the switches $S_{1}$ and $S_{3}$ are turned on but the switches $S_{2}$ and $S_{4}$ are turned off, whereas the diodes $D_{1}$ and $D_{3}$ are turned off but $D_{2}$ and $D_{4}$ are turned on. There are two loops in this state. The input voltage $V_{i n}$, the energy-transferring capacitor $C_{1}$, the inductor $L_{1}$, and the LED string $L S_{1}$ form one loop, so that the energy-transferring capacitor $C_{1}$ is charged while the inductor $L_{1}$ is magnetized. The energy-transferring capacitors $C_{2}$ and $C_{3}$, the inductor $L_{3}$ and the LED string $L S_{3}$ form the other loop, so that the energy-transferring capacitor $C_{3}$ is charged while the inductor $L_{3}$ is magnetized. The inductors $L_{2}$ and $L_{4}$ are demagnetized via the diodes $D_{2}$ and $D_{4}$, respectively. In this state, the voltages on the non-conducting diodes and switches are:

$$
\begin{gathered}
v_{D 1, \text { state } 1}=V_{\text {in }}-V_{C 1} \\
v_{D 3, \text { state } 1}=V_{C 2}-V_{C 3} \\
v_{d s 2, \text { state } 1}=V_{\text {in }}-V_{C 2} \\
v_{d s 4, \text { state } 1}=V_{C 3}
\end{gathered}
$$

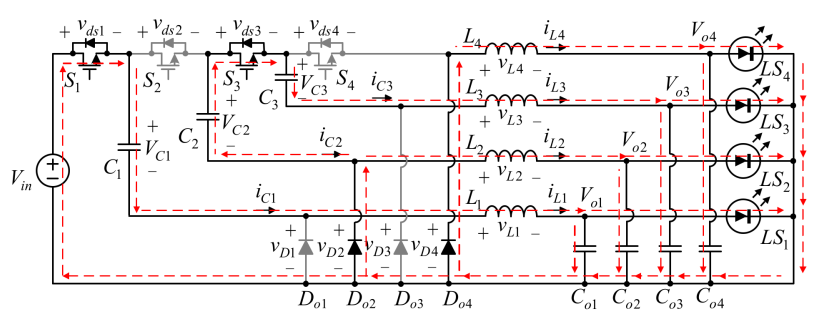

Figure 4. Current flow in state 1 in CCM.

States 2 and $4\left[t_{1} \leq t \leq t_{2}, t_{3} \leq t \leq t_{4}\right]$ : As shown in Figure 5 , the switches $S_{1}, S_{2}, S_{3}$ and $S_{4}$ are turned off, whereas the diodes $D_{1}, D_{2}, D_{3}$ and $D_{4}$ are turned on. At this time, the inductors $L_{1}, L_{2}, L_{3}$ and $L_{4}$ are demagnetized via the diodes $D_{1}, D_{2}, D_{3}$ and $D_{4}$, respectively. In this state, the voltages across the non-conducting switches are:

$$
\begin{gathered}
v_{d s 1, \text { state } 2}=V_{i n}-V_{C 1} \\
v_{d s 2, \text { state } 2}=V_{C 1}-V_{C 2} \\
v_{d s 3, \text { state } 2}=V_{C 2}-V_{C 3} \\
v_{d s 4, \text { state } 2}=V_{C 3}
\end{gathered}
$$

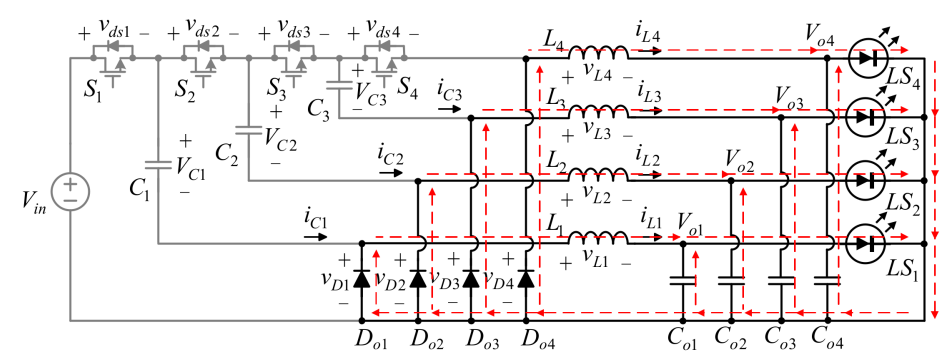

Figure 5. Current flow in states 2 and 4 in CCM.

State $3\left[t_{2} \leq t \leq t_{3}\right]$ : As shown in Figure 6, the switches $S_{2}$ and $S_{4}$ are turned on but $S_{1}$ and $S_{3}$ are turned off, whereas the diodes $D_{2}$ and $D_{4}$ are turned off but $D_{1}$ and $D_{3}$ are turned on. The energy-transferring capacitors $C_{1}$ and $C_{2}$, the inductor $L_{2}$, and the LED string $L S_{2}$ form a loop, so that the energy-transferring capacitor $C_{1}$ releases energy to the energy-transferring capacitor $C_{2}$, the inductor $L_{2}$, and the LED string $L S_{2}$. In addition, the 
energy-transferring capacitor $C_{3}$, the inductor $L_{4}$ and the LED string $L S_{4}$ also form a loop, so that the energy-transferring capacitor $C_{3}$ releases energy to the inductor $L_{4}$ and the LED string $L S_{4}$. At this time, the inductors $L_{1}$ and $L_{3}$ are demagnetized via diodes $D_{1}$ and $D_{3}$, respectively. In this state, the voltages across the non-conducting switches and diodes are:

$$
\begin{gathered}
v_{D 2, \text { state } 3}=V_{C 1}-V_{C 2} \\
v_{D 4, \text { state } 3}=V_{C 3} \\
v_{d s 1, \text { state } 3}=V_{i n}-V_{C 1} \\
v_{d s 3, \text { state } 3}=V_{C 1}-V_{C 3}
\end{gathered}
$$

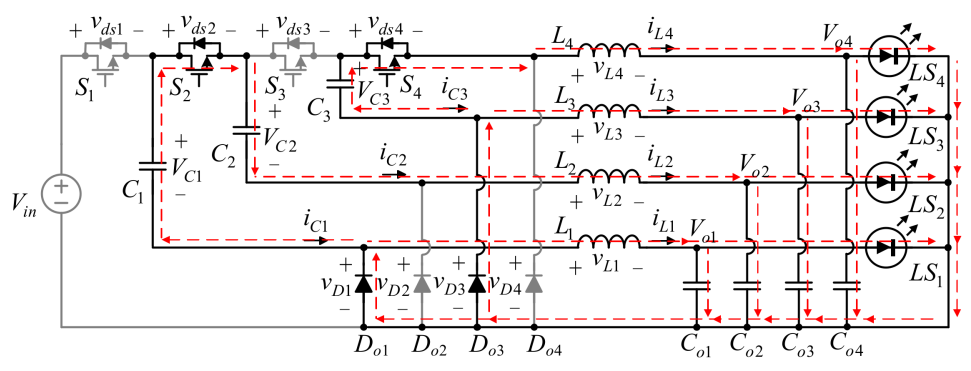

Figure 6. Current flow in state 3 in CCM.

2.2. Voltage Conversion Ratio $M$ in $C C M$ and Voltages on $C_{1}, C_{2}$ and $C_{3}$

By applying the volt-second balance to the inductors $L_{1}, L_{2}, L_{3}$ and $L_{4}$, the following equations can be obtained:

$$
\begin{gathered}
D\left(V_{i n}-V_{C 1}-V_{o 1}\right)+(1-D)\left(-V_{o 1}\right)=0 \\
D\left(V_{C 1}-V_{C 2}-V_{o 2}\right)+(1-D)\left(-V_{o 2}\right)=0 \\
D\left(V_{C 2}-V_{C 3}-V_{o 3}\right)+(1-D)\left(-V_{o 3}\right)=0 \\
D\left(V_{C 3}-V_{o 4}\right)+(1-D)\left(-V_{o 4}\right)=0
\end{gathered}
$$

In the case of exactly the same load, $V_{o 1}, V_{o 2}, V_{o 3}$, and $V_{04}$ in the above equations can be regarded as fixed values of $V_{o}$. Then, the voltage conversion ratio $M$ and the voltages across the energy-transferring capacitors, called $V_{C 1}, V_{C 2}$ and $V_{C 3}$, can be obtained by rearranging the above equations:

$$
\begin{gathered}
M=\frac{V_{o}}{V_{i n}}=\frac{D}{4} \\
V_{C 1}=3 \times \frac{V_{o}}{D}=\frac{3}{4} V_{\text {in }} \\
V_{C 2}=2 \times \frac{V_{o}}{D}=\frac{V_{\text {in }}}{2} \\
V_{C 3}=\frac{V_{o}}{D}=\frac{V_{i n}}{4}
\end{gathered}
$$

\subsection{Converter Operating in Discontinuous Conduction Mode (DCM)}

Prior to the circuit operation analysis, some related symbol definitions and required assumptions in DCM are the same as those in CCM. The relevant waveforms in the circuit are shown in Figure 7. Furthermore, it is assumed that the demagnetization time of the four inductors in the circuit is the same, and its value is $D_{2} T_{S}$ and the four output voltages are clamped by the four LED strings so $V_{01}=V_{o 2}=V_{03}=V_{04}=V_{o}$. In addition, $v_{d s i, \text { statey }}$ 
means the voltage across the $\mathrm{i}$-th switch during the $\mathrm{y}$-th state, whereas $v_{D i, s t a t e y}$ means the voltage across the $\mathrm{i}$-th diode during the $\mathrm{y}$-th state.

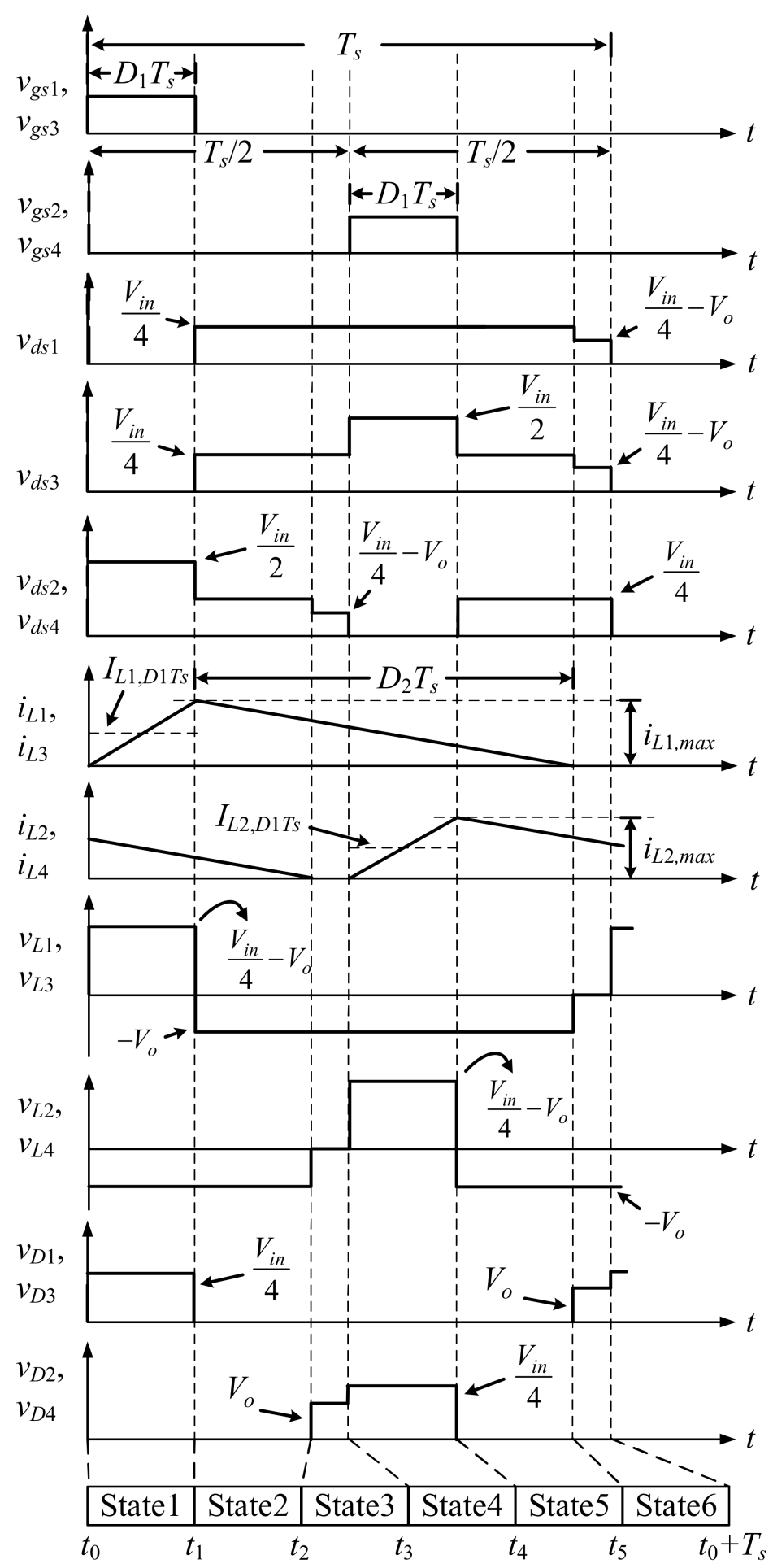

Figure 7. Waveforms relevant to the converter operating in DCM.

State $1\left[t_{0} \leq t \leq t_{1}\right]$ : The circuit operation in state 1 under DCM and the circuit operation in state 1 under CCM are the same, and this will not be redescribed herein.

State $2\left[t_{1} \leq t \leq t_{2}\right]$ : The circuit operation in state 2 under DCM and the circuit operation in state 2 under CCM are the same, and this will not be redescribed herein.

State $3\left[t_{2} \leq t \leq t_{3}\right]$ : As shown in Figure 8, the difference from state 2 is that the inductors $L_{2}$ and $L_{4}$ have been demagnetized entirely at this time and the currents in these 
two inductors are both zero. In this state, the voltages across the non-conducting switches and diode are:

$$
\begin{gathered}
v_{D 2, \text { state } 3}=v_{D 4, \text { state } 3}=V_{o} \\
v_{d s 1, \text { state } 3}=V_{i n}-V_{C 1} \\
v_{d s 2, \text { state } 3}=V_{C 1}-V_{C 2}-V_{o} \\
v_{d s 3, \text { state } 3}=V_{C 2}-V_{C 3}-V_{o} \\
v_{d s 4, \text { state3 }}=V_{C 3}-V_{o}
\end{gathered}
$$

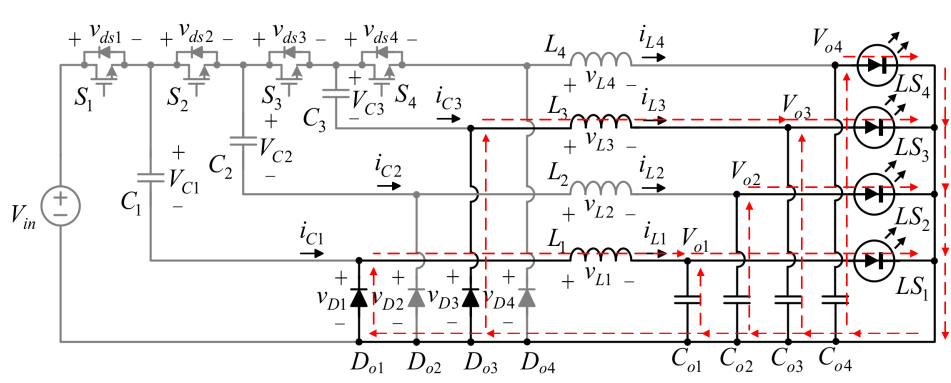

Figure 8. Current flow in state 3 in DCM.

State $4\left[t_{3} \leq t \leq t_{4}\right]$ : The circuit operation in state 4 under DCM and the circuit operation in state 3 under CCM are the same, and this will not be redescribed herein.

State $5\left[t_{4} \leq t \leq t_{5}\right]$ : The circuit operation in state 5 under DCM and the circuit operation in state 4 under CCM are the same, and this will not be redescribed herein.

State $6\left[t_{5} \leq t \leq t_{0}+T_{s}\right]$ : As shown in Figure 9, the difference from state 2 is that the inductors $L_{1}$ and $L_{3}$ have been demagnetized entirely at this time, and the currents in these two inductors are both zero. In this state, the voltages across the non-conducting diode and switches are:

$$
\begin{gathered}
v_{D 1, \text { state6 }}=v_{D 3, \text { state6 }}=V_{o} \\
v_{d s 1, \text { state6 }}=V_{i n}-V_{C 1}-V_{o} \\
v_{d s 2, \text { state6 }}=V_{C 1}-V_{C 2}-V_{o} \\
v_{d s 3, \text { state6 }}=V_{C 2}-V_{C 3}-V_{o} \\
v_{d s 4, \text { state6 }}=V_{C 3}-V_{o}
\end{gathered}
$$

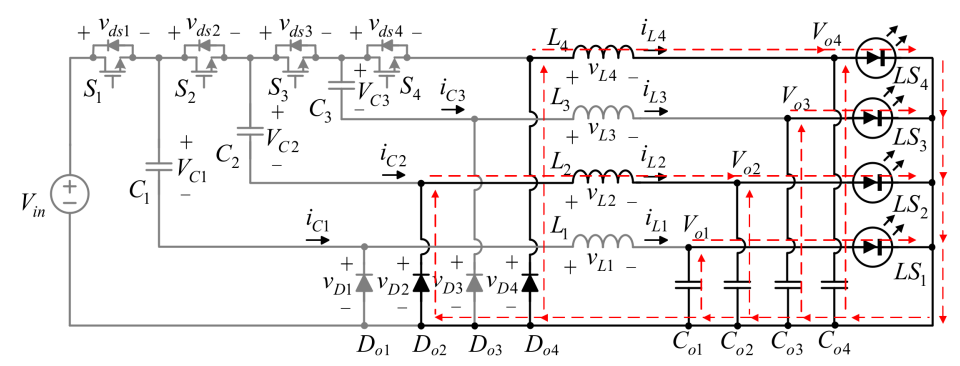

Figure 9. Current flow in state 6 in DCM.

2.4. Voltage Conversion Ratio $M$ in DCM and Voltages on $C_{1}, C_{2}$ and $C_{3}$

By applying the volt-second balance to the inductors $L_{1}, L_{2}, L_{3}$ and $L_{4}$, the following equations can be obtained:

$$
\left(V_{\text {in }}-V_{C 1}-V_{o}\right) \times D_{1} T_{s}+\left(-V_{o}\right) \times D_{2} T_{s}=0
$$




$$
\begin{gathered}
\left(V_{C 1}-V_{C 2}-V_{o}\right) \times D_{1} T_{s}+\left(-V_{o}\right) \times D_{2} T_{s}=0 \\
\left(V_{C 2}-V_{C 3}-V_{o}\right) \times D_{1} T_{s}+\left(-V_{o}\right) \times D_{2} T_{s}=0 \\
\left(V_{C 3}-V_{o}\right) \times D_{1} T_{s}+\left(-V_{o}\right) \times D_{2} T_{s}=0
\end{gathered}
$$

Then, after sorting (34) and substituting it back to (31), (32) and (33), the voltages across the energy-transferring capacitors, called $V_{C 1}, V_{C 2}$ and $V_{C 3}$, and the relationship between $V_{\text {in }}$ and $V_{o}$ can be obtained, respectively:

$$
\begin{gathered}
V_{C 3}=\frac{D_{1}+D_{2}}{D_{1}} \times V_{o}=\frac{1}{4} V_{i n} \\
V_{C 2}=\frac{D_{1}+D_{2}}{D_{1}} \times 2 V_{o}=\frac{1}{2} V_{i n} \\
V_{C 1}=\frac{D_{1}+D_{2}}{D_{1}} \times 3 V_{o}=\frac{3}{4} V_{i n} \\
V_{\text {in }}=\frac{D_{1}+D_{2}}{D_{1}} \times 4 V_{o}
\end{gathered}
$$

Since the output current will be equal to the average value of the inductor current, it can be obtained that the relational expression is as shown in (39), where $R$ signifies the equivalent resistance of the LED, equal to the LED forward voltage divided by the LED forward current, and $i_{L 1, \max }$ is the maximum current in $L_{1}$ :

$$
\frac{1}{2} \times i_{L 1, \max } \times\left(D_{1}+D_{2}\right)=I_{o 1}=\frac{V_{o}}{R}
$$

According to the inductor voltage and current formula, it can be known that:

$$
D_{2} T_{S}=\frac{L_{1} \times i_{L 1, \max }}{V_{o}}=\frac{2 L_{1}}{R\left(D_{1}+D_{2}\right)}
$$

Then, by substituting (41) into (40) and solving out, (42) can be obtained:

$$
\begin{gathered}
K \equiv \frac{2 L_{1}}{R T_{s}} \\
D_{2}^{2}+D_{1} D_{2}-K=0 \\
\Rightarrow D_{2}=D_{1} \times \frac{\sqrt{1+\frac{4 K}{D_{1}^{2}}}-1}{2}
\end{gathered}
$$

Eventually, by substituting (42) into (38) can obtain the voltage conversion ratio $M$ :

$$
M=\frac{V_{o}}{V_{\text {in }}}=\frac{1}{2\left[1+\sqrt{\frac{4 K}{D_{1}^{2}}+1}\right]}
$$

From (43), the voltage conversion ratio $M$ in $D C M$ is related to the load.

\subsection{Boundary Condition for Inductor $L_{1}$}

Since the current ripple $\Delta i_{L 1}$ flowing through the inductor $L_{1}$ can be expressed as:

$$
\Delta i_{L 1}=\frac{v_{L i} \Delta t}{L_{1}}=\frac{\left(V_{i n}-V_{C 1}-V_{o}\right) \times D T_{S}}{L_{1}}
$$


As $I_{L 1} \geq \frac{\Delta i_{L 1}}{2}$, the inductor $L_{1}$ will operate in CCM, namely:

$$
\begin{aligned}
& I_{L 1} \geq \frac{\Delta i_{L 1}}{2} \\
& \Rightarrow I_{L 1} \geq \frac{\left(V_{i n}-V_{C 1}-V_{o}\right) \times D T_{s}}{2 \times L_{1}} \\
& \Rightarrow L_{1} \geq \frac{\left(V_{i n}-V_{C 1}-V_{0}\right) \times D T_{s}}{2 \times I_{01}}
\end{aligned}
$$

As (45) is satisfied, the inductor $L_{1}$ operates in CCM; otherwise, it operates in DCM.

\subsection{Boundary Condition for Inductors $L_{2}, L_{3}$ and $L_{4}$}

As the boundary condition analyses for the inductors $L_{2}, L_{3}$, and $L_{4}$ are the same as that for the inductor $L_{1}$, it will not be redescribed herein.

\subsection{Analysis of Automatic Current Sharing Principle}

The principle of automatic current sharing in DCM is the same as that in CCM. The average values of the charging and discharging currents of the energy-transferring capacitors $C_{1}, C_{2}$, and $C_{3}$ are the same, so automatic current sharing between four phases can be achieved.

\subsection{Structure Extension}

The proposed LED driver can be extended to six phases as shown in Figure 10. Its operating principle is the same as that of the proposed LED driver. As long as the adjacent switches are not turned on at the same time and the duty cycle is not larger than 0.5 , the automatic current sharing of multiple strings of LEDs can be achieved. Although the extended circuit has more components, it has a lower voltage conversion ratio.

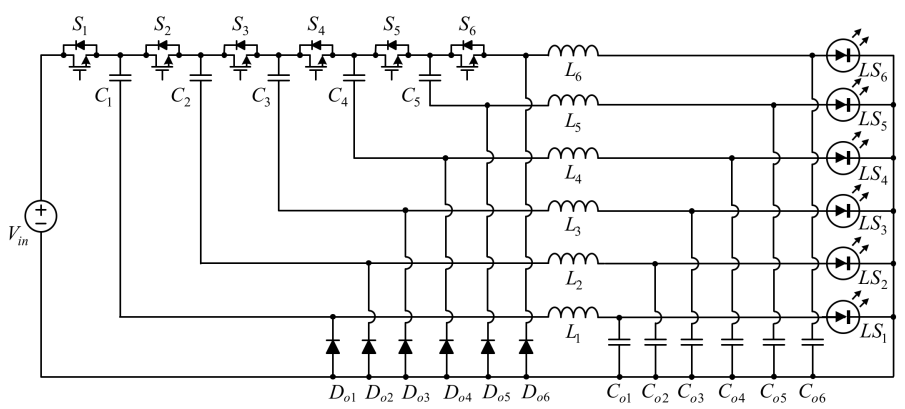

Figure 10. Six-phase LED driver.

\section{Design Considerations}

Figure 11 is the LED drive circuit with automatic current sharing proposed. The system includes the main power stage and the feedback control circuit. As for the feedback control circuit, it uses the current detection IC, named ACS712, to obtain the analog signal of the output current. Then, based on the sampling without ADC technique [18], the corresponding digital signal is obtained and sent to the FPGA for calculation to create the required digital control force. Such a digital control force is sent to a gate driver TLP250H with galvanic isolation function to control the switch.

Table 1 shows the system specifications. Because the current is small in the light load, the inductance will be too large if all this load is operated in CCM. So, $25 \%$ of the rated load is designed in DCM. Table 2 shows the LED specifications. The LEDs used are high-brightness LEDs manufactured EVERLIGHT Electronics Co., Ltd. Table 3 shows a summary of the components of the proposed circuit. Table 4 shows the FPGA specifications. 


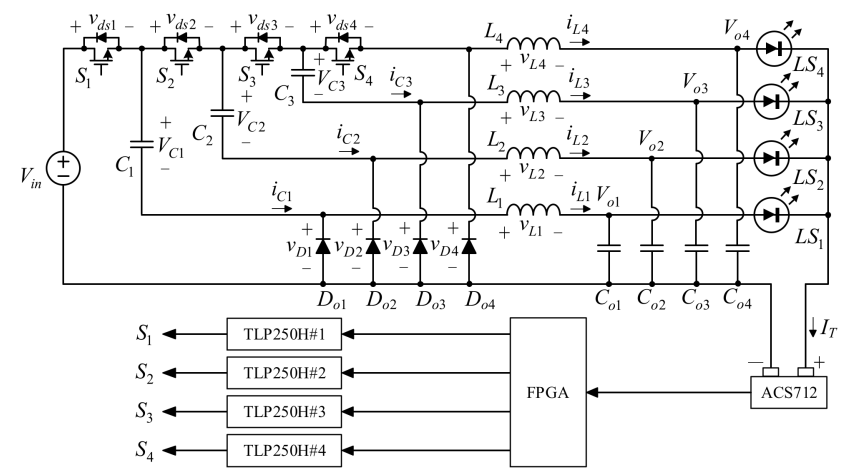

Figure 11. System configuration diagram.

Table 1. System specifications.

\begin{tabular}{|c|c|}
\hline Parameter Name & Value \\
\hline System operation mode & $\begin{array}{l}\text { Rated loaded: CCM } \\
\text { Half load: CCM } \\
\text { Light load: DCM }\end{array}$ \\
\hline Rated input voltage $\left(V_{\text {in }}\right)$ & $400 \mathrm{~V}$ \\
\hline Rated output voltage $\left(V_{o}\right)$ & $27.6 \mathrm{~V}(=3.45 \times 8)$ \\
\hline Rated output current $\left(I_{o, \text { arted }}\right)$ & $1.4 \mathrm{~A}(=0.35 \mathrm{~A} \times 4)$ \\
\hline Rated output power $\left(P_{o, \text { rated }}\right)$ & $38.64 \mathrm{~W}$ \\
\hline Minimum output current under CCM $\left(I_{o, \min , \mathrm{CCM}}\right) /$ power $\left(P_{o, \min , \mathrm{CCM}}\right)$ & $0.175 \mathrm{~A} / 17.36 \mathrm{~W}$ \\
\hline Minimum output current under DCM $\left(I_{0, \min , D C M}\right) /$ power $\left(P_{o, \min , D C M}\right)$ & $0.0875 \mathrm{~A} / 8.12 \mathrm{~W}$ \\
\hline Switching frequency $\left(f_{s}\right) /$ period $\left(T_{s}\right)$ & $100 \mathrm{kHz} / 10 \mu \mathrm{s}$ \\
\hline
\end{tabular}

Table 2. LED specifications.

\begin{tabular}{cc}
\hline Parameter Name & Value \\
\hline Forward voltage $\left(V_{F}\right)$ & $2.95 \mathrm{~V} \sim 3.85 \mathrm{~V}$ with a typical value of $3.45 \mathrm{~V}$ \\
\hline DC operating current $\left(I_{F, \max }\right)$ & $400 \mathrm{~mA}$ \\
\hline Pulsed forward current & $500 \mathrm{~mA}$ \\
\hline Junction temperature & $125^{\circ} \mathrm{C}$ \\
\hline Operating temperature & $-40{ }^{\circ} \mathrm{C} \sim+85^{\circ} \mathrm{C}$ \\
\hline Typical light flux output & $100 \mathrm{~lm} @ 350 \mathrm{~mA}$ \\
\hline
\end{tabular}

Table 3. Component specifications.

\begin{tabular}{cc}
\hline Component & Product Name \\
\hline$S_{1}, S_{2}, S_{3}, S_{4}$ & SPA07N60C3 \\
\hline$D_{1}, D_{2}, D_{3}, D_{4}$ & DSEP8-02A \\
\hline$C_{1}, C_{2}, C_{3}$ & $47 \mu \mathrm{F} / 400 \mathrm{~V}$ LTEC electrolytic capacitor \\
\hline$C_{o 1}, C_{o 2}, C_{o 3}, C_{04}$ & $220 \mu \mathrm{F} / 50 \mathrm{~V}$ electrolytic capacitor \\
\hline$L_{1}, L_{2}, L_{3}, L_{4}$ & Core: PQ20/16 $L_{1}=603.5 \mu \mathrm{H}, L_{2}=601.7 \mu \mathrm{H}, L_{3}=598.2 \mu \mathrm{H}, L_{4}=599.1 \mu \mathrm{H}$ \\
\hline Gate driver & TLP250H \\
\hline Current sensor & ACS712 \\
\hline LED & EHP-AX08EL/GT01H-P01/5670/Y /K42 \\
\hline
\end{tabular}


Table 4. EP3C5E144C8N specifications.

\begin{tabular}{cccccc}
\hline Device & $\begin{array}{c}\text { Logic } \\
\text { Elements }\end{array}$ & $\begin{array}{c}\text { Total RAM } \\
\text { Bits }\end{array}$ & $\begin{array}{c}\mathbf{1 8 \times 1 8} \\
\text { Multipliers }\end{array}$ & PLLs & $\begin{array}{c}\text { User I/O } \\
\text { Pins }\end{array}$ \\
\hline EP3C5E144C8N & 5136 & 423,936 & 23 & 2 & 94 \\
\hline
\end{tabular}

\subsection{Design of Inductors $L_{1}, L_{2}, L_{3}$ and $L_{4}$}

The circuit operating principle in CCM has been described in Section 2.1, the behavior of the four inductors is the same if these inductors are identical, so the following only focuses on design of the first inductor $L_{1}$. From (17), the duty cycle D can be expressed to be:

$$
D=\frac{4 V_{o}}{V_{\text {in }}}
$$

Based on Table 2 and (46), the corresponding duty cycles for $100 \%$ and $50 \%$ loads are 0.276 and 0.248 , respectively, to be calculated as follows:

$$
\begin{gathered}
D_{100 \% \text { Load }}=\frac{4 V_{o}}{V_{\text {in }}}=\frac{4 \times 8 \times 3.45}{400}=0.276 \\
D_{50 \% \text { Load }}=\frac{4 V_{o}}{V_{\text {in }}}=\frac{4 \times 8 \times 3.1}{400}=0.248
\end{gathered}
$$

If the inductor is to operate in inductive current continuous mode, the value of inductor $L_{1}$ must meet the inequalities (45):

$$
\begin{aligned}
L_{1} & \geq \frac{\left(V_{i n}-V_{C 1}-V_{o}\right) \times D T_{s}}{2 \times I_{L 1}} \\
& =\frac{(400-300-24.8) \times 0.248 \times 10^{-5}}{2 \times 0.175} \\
& \cong 532.85 \mu \mathrm{H}
\end{aligned}
$$

By the same way for $L_{2}, L_{3}$ and $L_{4}$, the values for $L_{1}, L_{2}, L_{3}$ and $L_{4}$ are finally chosen to be $603.5 \mu \mathrm{H}, 601.7 \mu \mathrm{H}, 598.2 \mu \mathrm{H}$ and $599.1 \mu \mathrm{H}$, respectively.

\subsection{Design of Energy-Transferring Capacitors $C_{1}, C_{2}$ and $C_{3}$}

From Figure 12, it can be seen that during the period of $D T_{s}$, the constant current of $C_{1}$, called $I_{C 1, D T s}$, is the same as that of $L_{1}$, called $I_{L 1, D T s}$, that is,

$$
I_{C 1, D T s}=I_{L 1, D T s}=I_{L 1}
$$

Substituting the rated input voltage $V_{\text {in }}$ shown in Table 1 into (18), the DC voltage across $C_{1}$ is:

$$
V_{\mathrm{C} 1}=300 \mathrm{~V}
$$

Assume that the peak-to-peak voltage ripple $\Delta v_{C}$ is within $0.1 \%$ of $V_{C 1}$, and the corresponding inequality is:

$$
\begin{aligned}
C_{1} & \geq \frac{I_{C 1, D T s} \cdot D T_{s}}{\Delta v_{C 1}} \\
& =\frac{I_{L 1} \cdot D T_{s}}{0.1 \% \times V_{C 1}} \\
& =\frac{0.35 \times 0.276 \times 10 \mu}{0.001 \times 300}=3.22 \mu \mathrm{F}
\end{aligned}
$$

By the same way for $C_{2}$ and $C_{3}$ and considering the effect of switching frequency on electrolytic capacitance, the values for $C_{1}, C_{2}$, and $C_{3}$ are all set at $47 \mu \mathrm{F} / 400 \mathrm{~V}$ based on measurements from the LCR meter. 


\subsection{Design of Output Capacitors $C_{01}, C_{02}$ and $C_{03}$}

Assume that the peak-to-peak voltage ripple $\Delta v_{C_{01}}$ is within $0.1 \%$ of $V_{o 1}$, and the corresponding inequality is:

$$
\begin{aligned}
C_{o 1} & \geq \frac{\Delta i_{L 1} \times T_{s}}{8 \times \Delta v_{C 01}} \\
& =\frac{0.34 \times 10^{-5}}{8 \times 0.001 \times 27.6}=15.4 \mu \mathrm{F}
\end{aligned}
$$

By the same way for $C_{02}, C_{03}$ and $C_{04}$ and considering the effect of switching frequency on electrolytic capacitance, the values for $C_{1}, C_{2}$, and $C_{3}$ are all set at $220 \mu \mathrm{F} / 50 \mathrm{~V}$ based on measurements from the LCR meter.

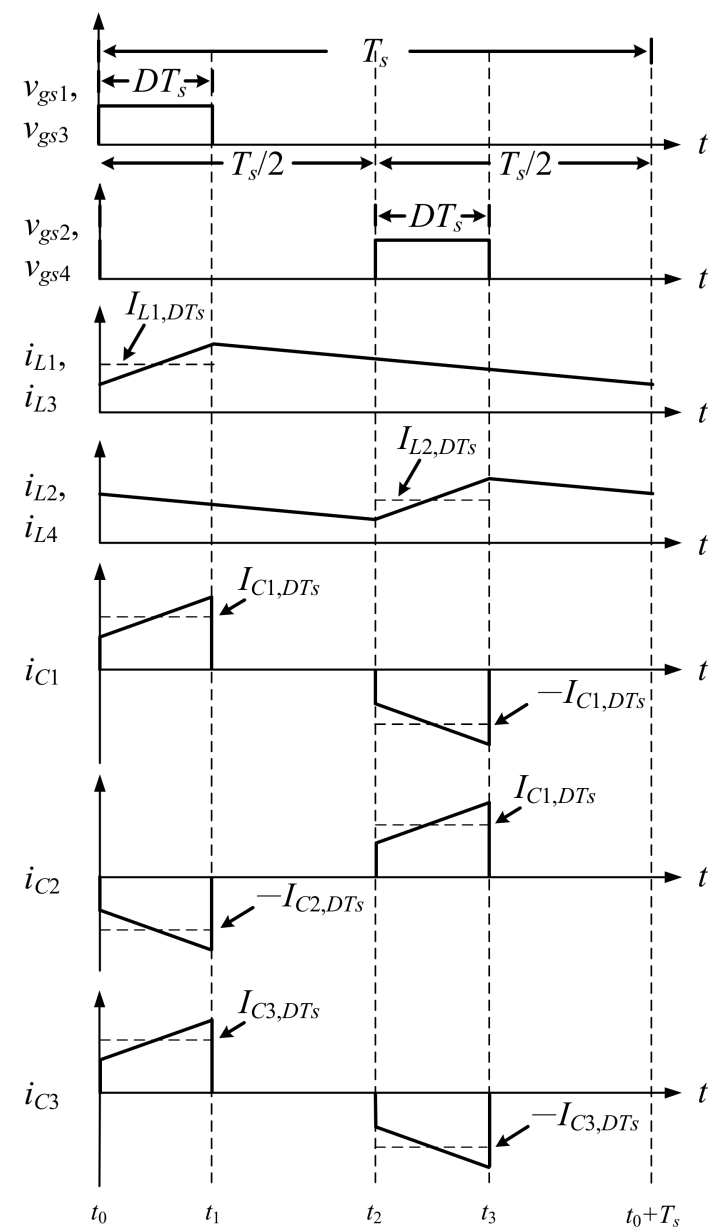

Figure 12. Current waveforms relevant to energy-transferring capacitors $C_{1}, C_{2}$ and $C_{3}$.

\section{Experimental Results}

\subsection{Measured Waveforms}

Figure 13 is a photo of the proposed LED driver. Figures 14-21 are obtained at rated load in CCM whereas Figures 22-29 are obtained at 25\% rated load in DCM. From Figures 15, 16, 23 and 24, under any two loads, except for the voltage across switch $S_{1}, v_{d s} 1$, the voltages across the switches $S_{2}, S_{3}$ and $S_{4}$ are all in a three-stage form, and the voltage stress on switch $S_{1}$ is the smallest, which is $100 \mathrm{~V}$ ( 0.25 times of the input voltage), and the voltage stresses on switches $S_{2}, S_{3}$, and $S_{4}$ are all $200 \mathrm{~V}$ ( 0.5 times the input voltage). 


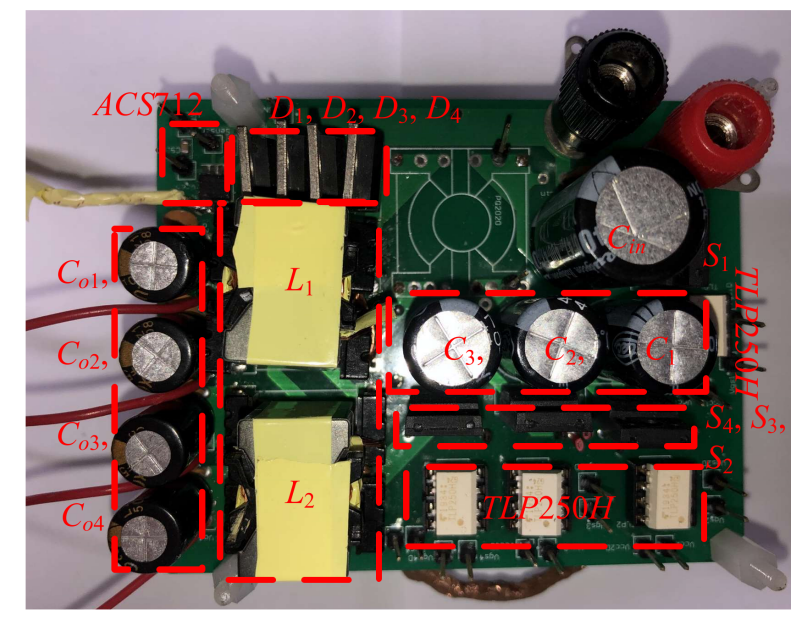

Figure 13. Photo of experimental setup.

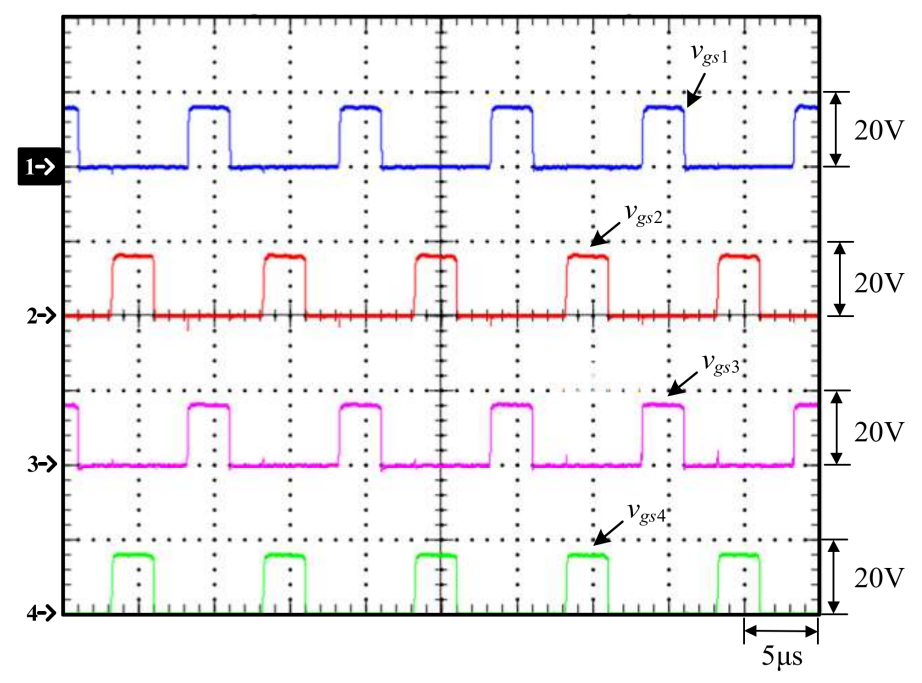

Figure 14. Measured waveforms relevant to rated load: (1) $v_{g s 1} ;(2) v_{g s 2} ;(3) v_{g s 3} ;(4) v_{g s 4}$.

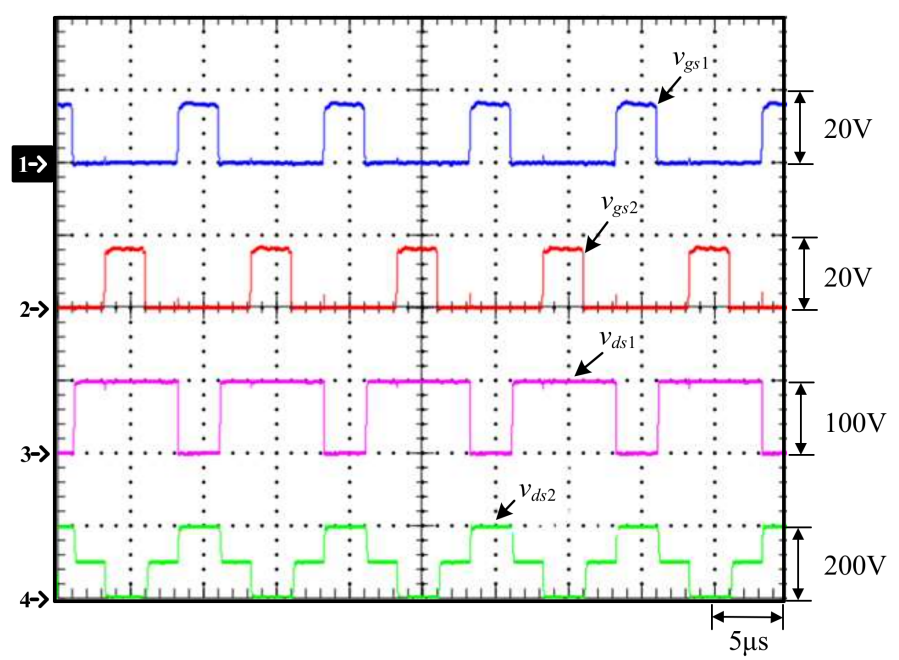

Figure 15. Measured waveforms relevant to rated load: (1) $v_{g s 1} ;$ (2) $v_{g s 2} ;(3) v_{d s 1} ;$ (4) $v_{d s 2}$. 


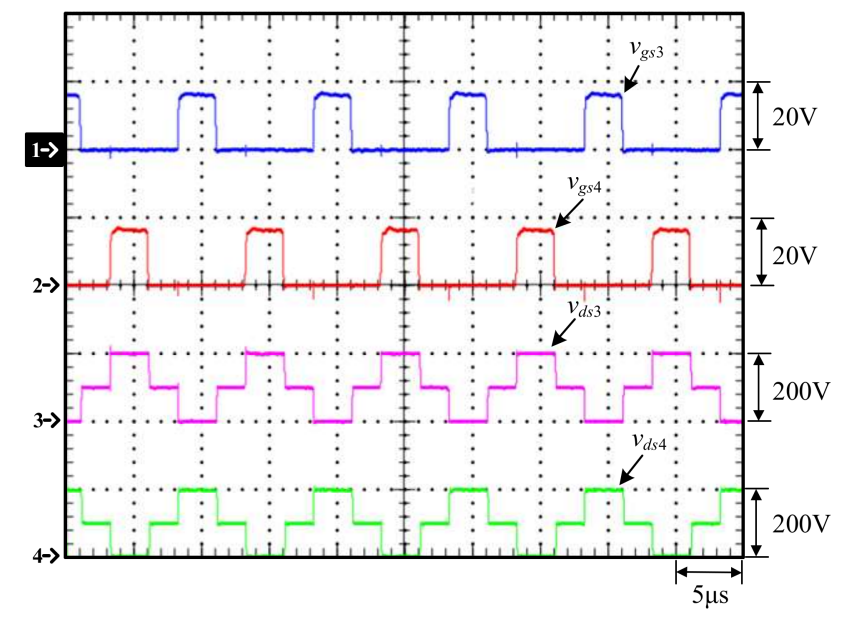

Figure 16. Measured waveforms relevant to rated load: (1) $v_{g s 3} ;$ (2) $v_{g s 4} ;(3) v_{d s 3} ;$ (4) $v_{d s 4}$.

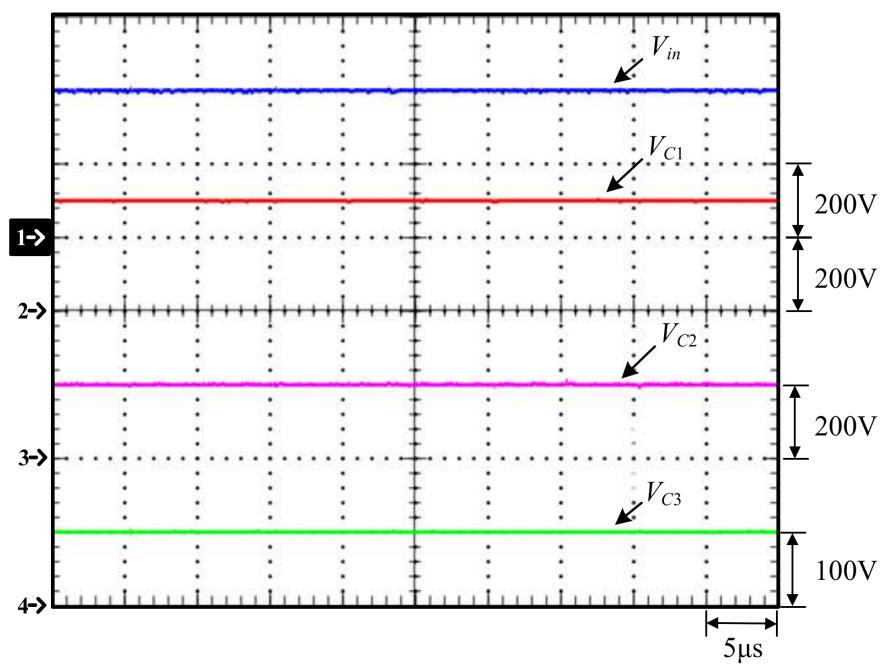

Figure 17. Measured waveforms relevant to rated load: (1) $V_{\text {in }}$; (2) $V_{C 1}$; (3) $V_{C 2}$; (4) $V_{C 3}$.

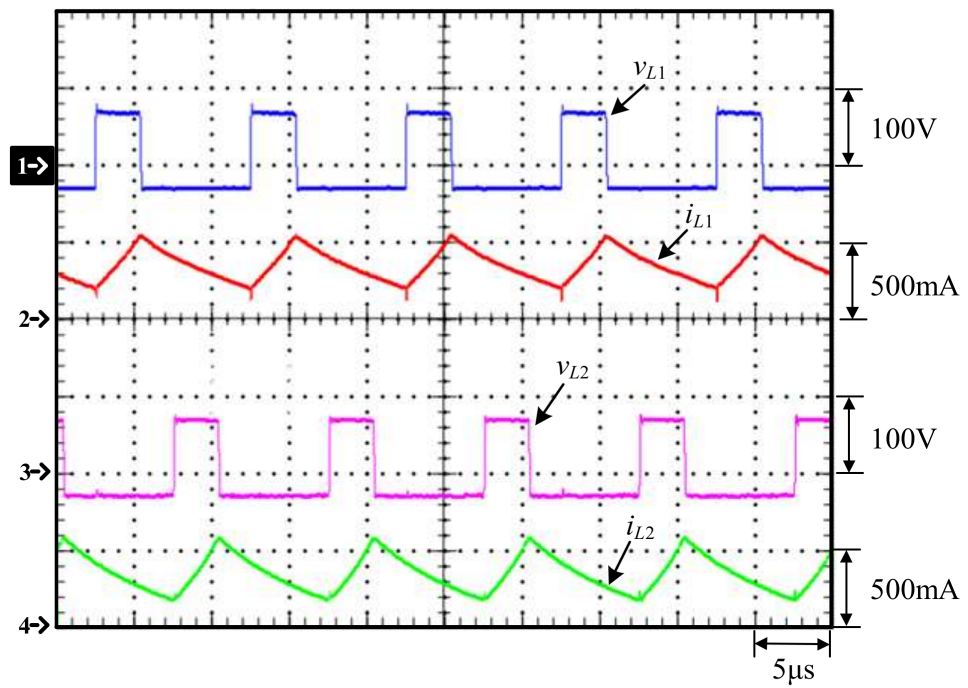

Figure 18. Measured waveforms relevant to rated load: (1) $v_{L 1} ;(2) i_{L 1} ;(3) v_{L 2} ;(4) i_{L 2}$. 


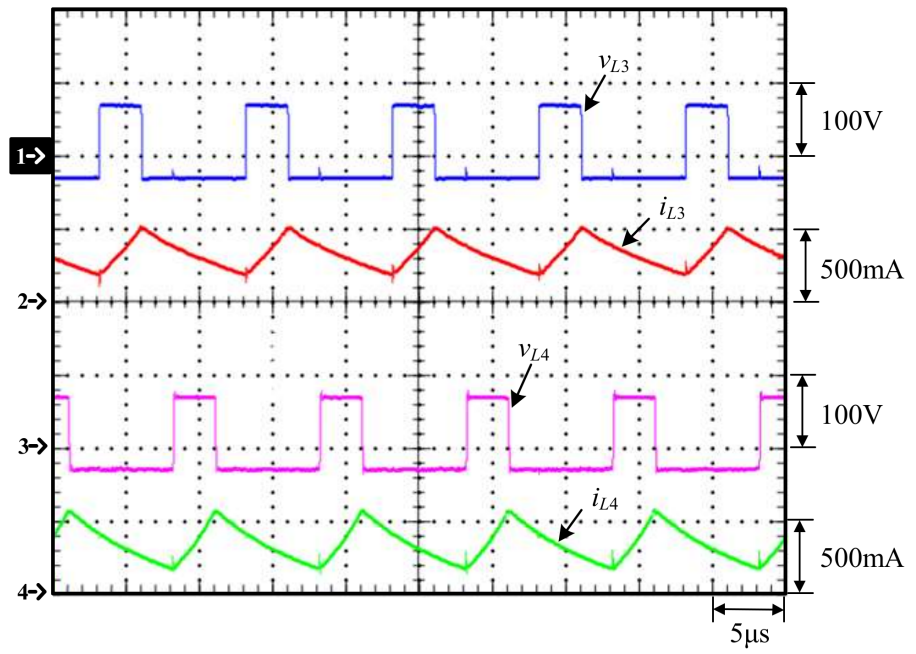

Figure 19. Measured waveforms relevant to rated load: (1) $v_{L 3} ;(2) i_{L 3} ;(3) v_{L 4} ;(4) i_{L 4}$.

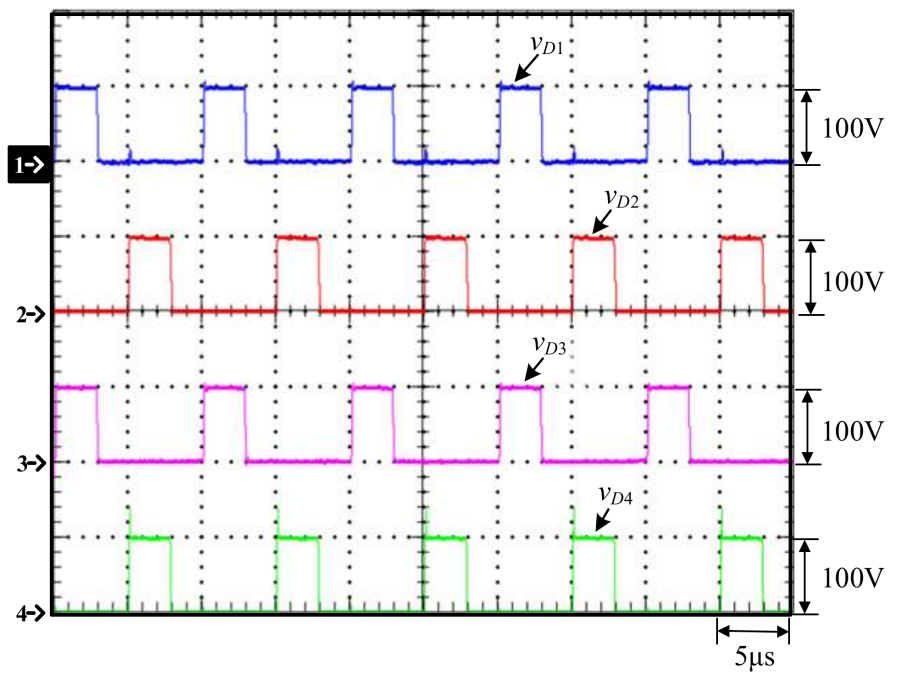

Figure 20. Measured waveforms relevant to rated load: (1) $v_{D 1} ;(2) v_{D 2} ;$ (3) $v_{D 3} ;$ (4) $v_{D 4}$.

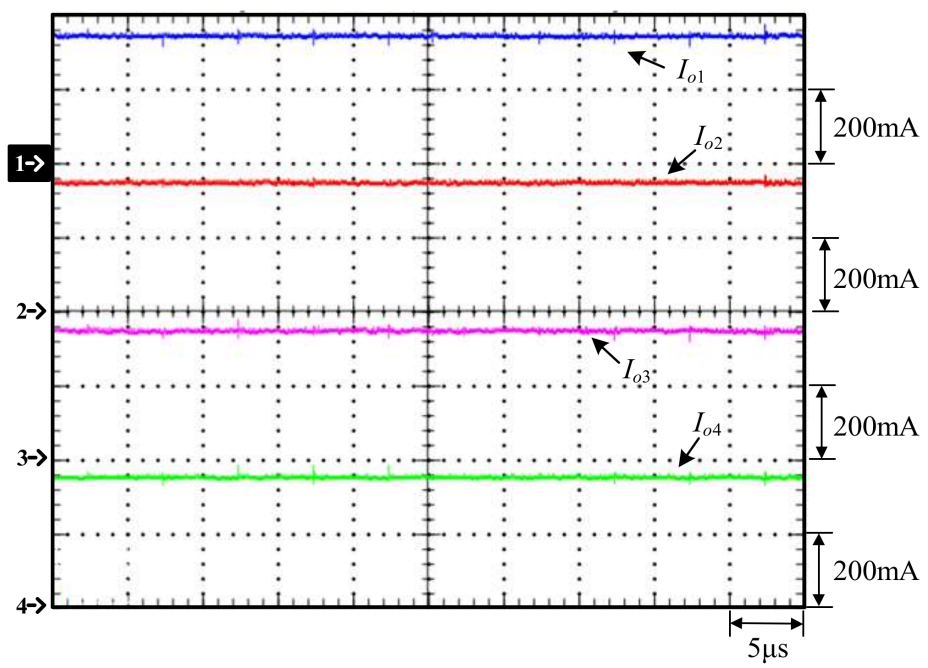

Figure 21. Measured waveforms relevant to rated load: (1) $I_{01}$; (2) $I_{o 2}$; (3) $I_{o 3}$; (4) $I_{04}$. 


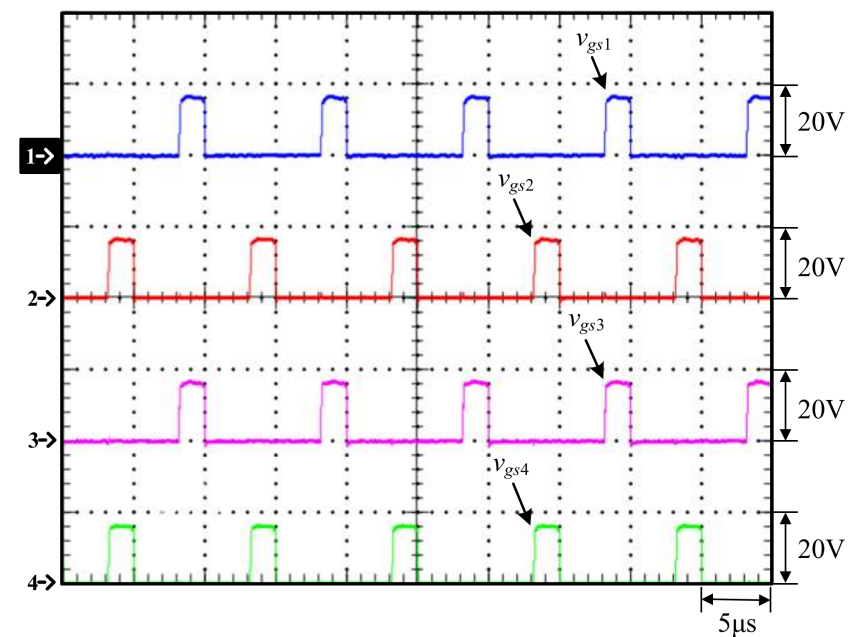

Figure 22. Measured waveforms relevant to $25 \%$ of the rated load: (1) $v_{g s} ;$; (2) $v_{g s 2} ;(3) v_{g s 3} ;$ (4) $v_{g s 4}$.

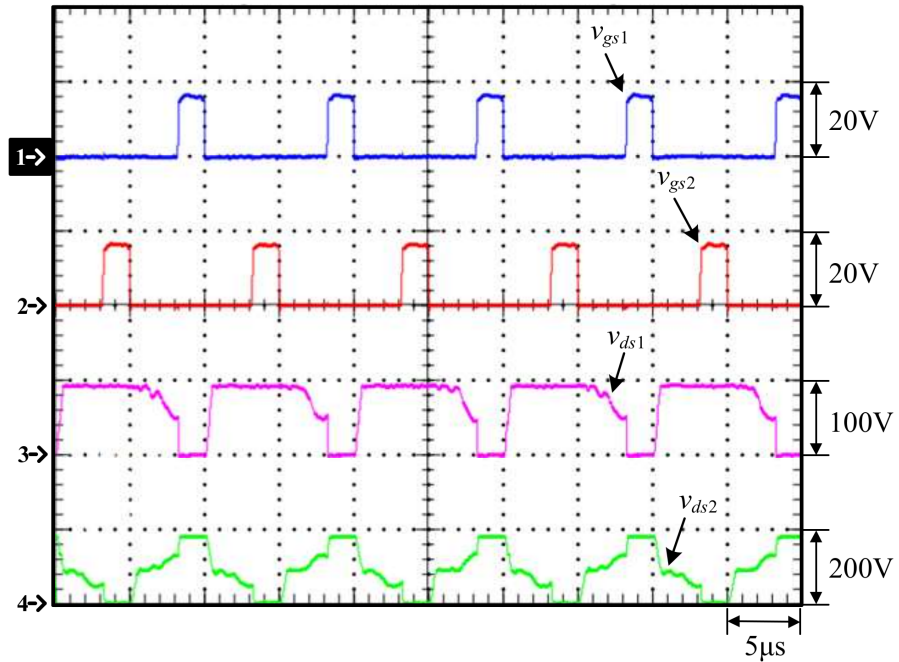

Figure 23. Measured waveforms relevant to $25 \%$ of the rated load: (1) $v_{g s 1} ;(2) v_{g s 2} ;(3) v_{d s 1}$; (4) $v_{d s 2}$.

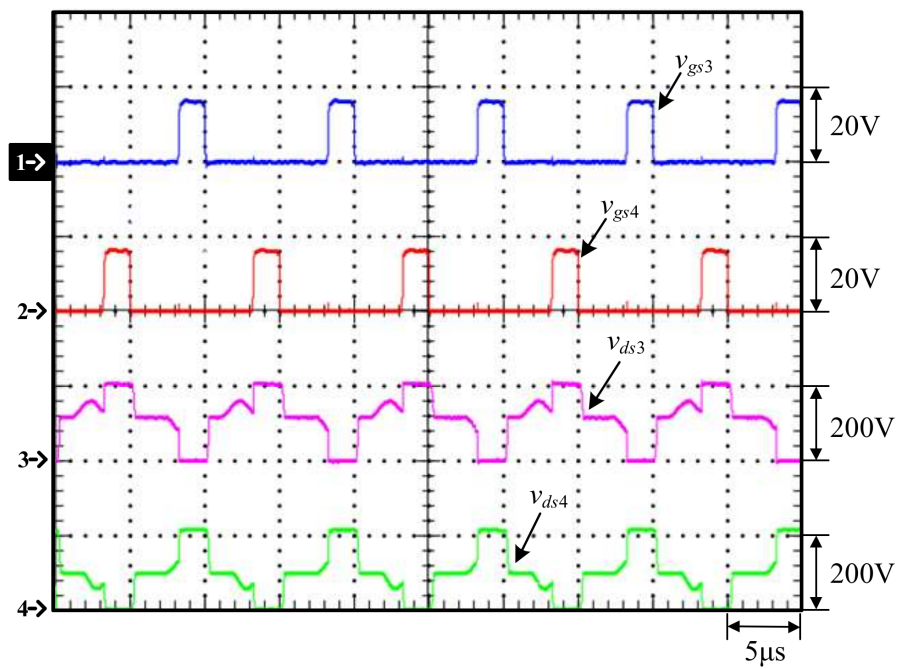

Figure 24. Measured waveforms relevant to $25 \%$ of the rated load: (1) $v_{g s 3} ;$ (2) $v_{g s} ;$ (3) $v_{d s 3} ;$ (4) $v_{d s}$. 


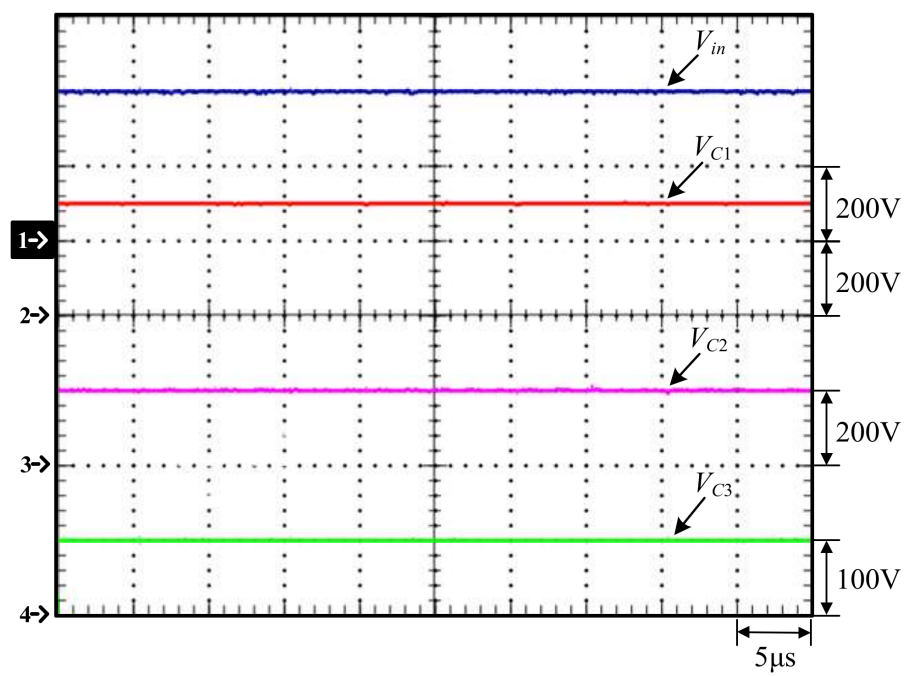

Figure 25. Measured waveforms relevant to $25 \%$ of the rated load: (1) $V_{\text {in }}$; (2) $V_{C 1}$; (3) $V_{C 2}$; (4) $V_{C 3}$.

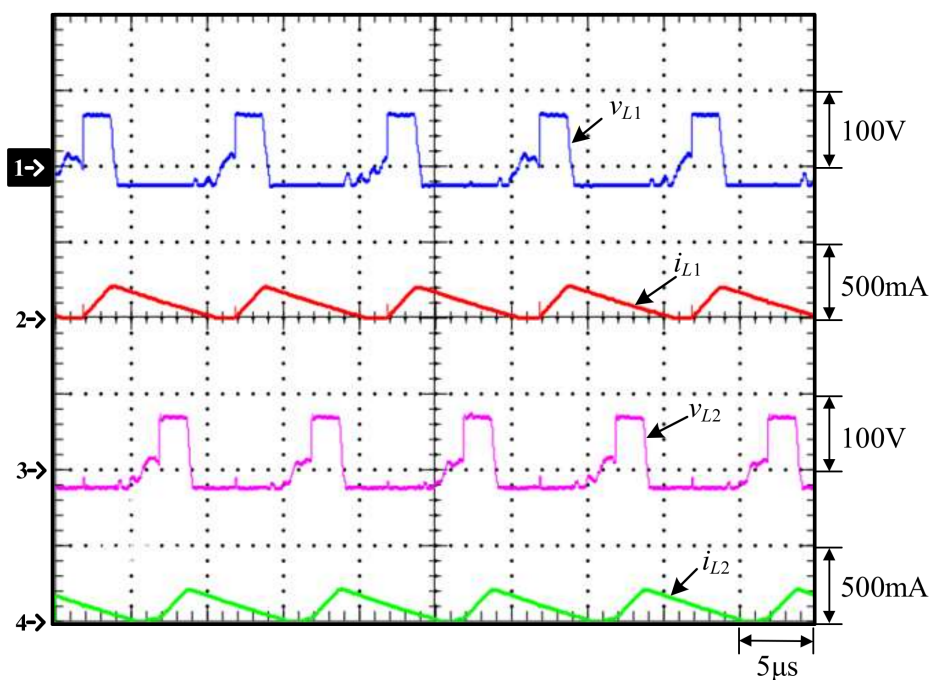

Figure 26. Measured waveforms relevant to $25 \%$ of the rated load: (1) $v_{L 1} ;(2) i_{L 1} ;(3) v_{L 2} ;(4) i_{L 2}$.

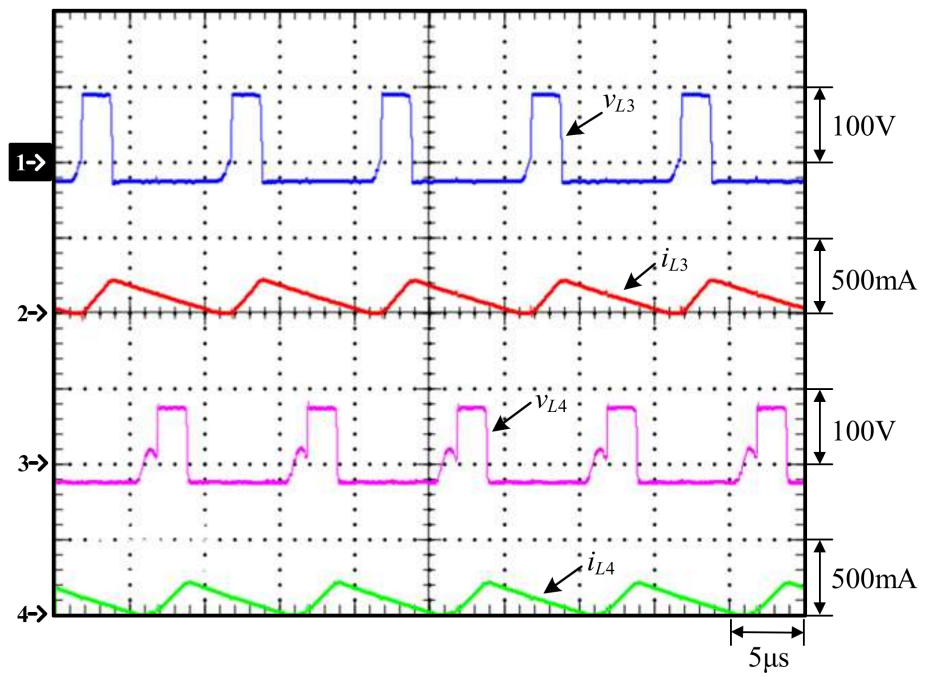

Figure 27. Measured waveforms relevant to $25 \%$ of the rated load: (1) $v_{L 3} ;$ (2) $i_{L 3} ;(3) v_{L 4} ;(4) i_{L 4}$. 


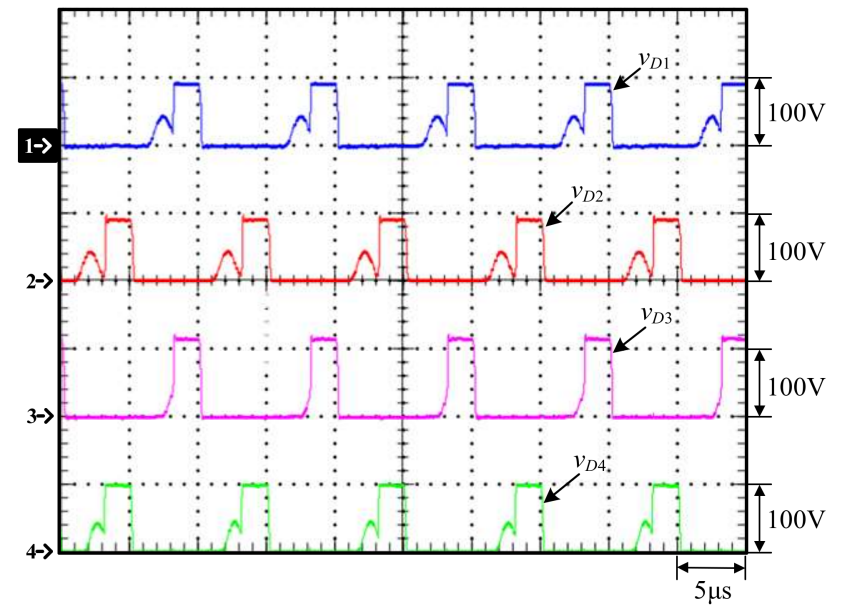

Figure 28. Measured waveforms relevant to $25 \%$ of the rated load: (1) $v_{D 1} ;$ (2) $v_{D 2} ;(3) v_{D 3} ;$ (4) $v_{D 4}$.

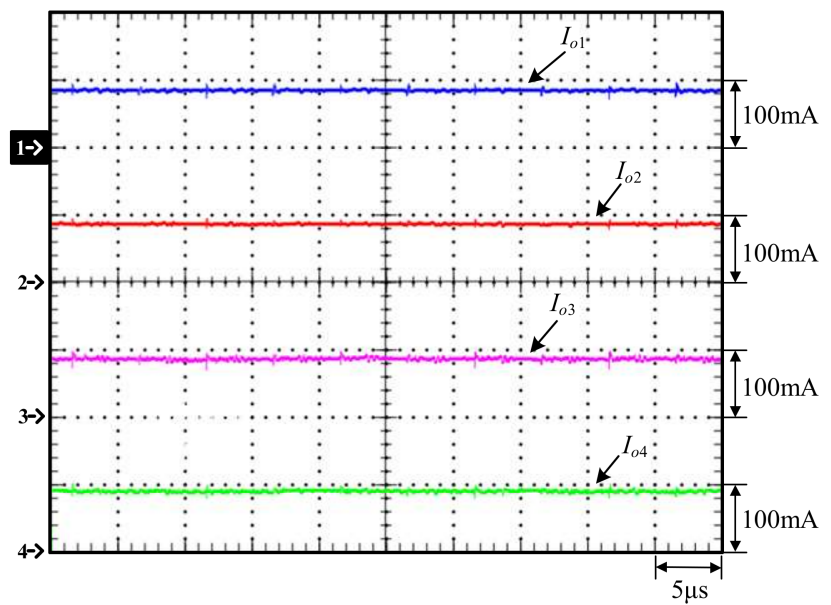

Figure 29. Measured waveforms relevant to $25 \%$ of the rated load: (1) $I_{01}$; (2) $I_{02} ;$ (3) $I_{03}$; (4) $I_{04}$.

From Figures 17 and 25, the voltages on three energy-transferring capacitors $C_{1}, C_{2}$, and $C_{3}$, called $V_{C 1}, V_{C 2}$ and $V_{C 3}$, are all stabilized at different certain voltage values, which will not vary with the load. Also, it can be known that from Figures 18, 19, 26 and 27, the DC values of the four inductor currents $i_{L 1}, i_{L 2}, i_{L 3}$ and $i_{L 4}$ are approximately the same under each load, implying that the load current can be evenly distributed among four phases. From Figures 20 and 28, under any load, the voltages on the four diodes $D_{1}, D_{2}, D_{3}$ and $D_{4}$ are all $100 \mathrm{~V}$ (0.25 times the input voltage). Furthermore, it can be known that from Figures 21 and 29, the output current can be evenly distributed among four phases.

In addition, in Figure 28, the voltage on the diode has a small resonance waveform before the cut-off. This is caused by the resonance of the parasitic capacitance on the diode and the inductance in the circuit, and will affect the voltages on the other components in the circuit, as shown in Figures 23, 24, 26 and 27.

\subsection{LED Current Error Percentage}

According to the experimental data measured above, the current error percentage of the LED string under different loads is calculated, as shown in Table 5. The current error percentage calculation formula used is:

$$
e_{y}=\frac{\left(I_{o y}-\frac{1}{n} \sum_{x=1}^{n} I_{o x}\right)}{\frac{1}{n} \sum_{x=1}^{n} I_{o x}} \times 100 \%
$$


where $e_{y}$ is the current error percentage of the $y$-th LED string, $n$ is the number of LED strings, and $I_{o y}$ is the current flowing through the y-th LED string, $\sum_{x=1}^{n} I_{o x}$ is the sum of all LED string currents. The values of $e_{y}$ can be obtained by using (54) and the current measurement values under different loads.

Table 5. Current error percentage under different loads.

\begin{tabular}{cccccc}
\hline $\begin{array}{c}\text { Load } \\
\text { Percentage }\end{array}$ & & $\boldsymbol{L S}_{\mathbf{1}}$ & $\boldsymbol{L} \boldsymbol{S}_{\mathbf{2}}$ & $\boldsymbol{L S}_{\mathbf{3}}$ & $\boldsymbol{L S}_{\mathbf{4}}$ \\
\hline \multirow{2}{*}{$100 \%$} & $I_{\text {on }}(\mathrm{mA})$ & 348 & 349 & 351 & 350 \\
\cline { 2 - 6 } & $e_{n}(\%)$ & 0.43 & 0.14 & -0.43 & -0.14 \\
\hline \multirow{2}{*}{$75 \%$} & $I_{\text {on }}(\mathrm{mA})$ & 259 & 257 & 260 & 261 \\
\cline { 2 - 6 } & $e_{n}(\%)$ & 0.096 & 0.87 & -0.29 & -0.67 \\
\hline \multirow{2}{*}{$50 \%$} & $I_{\text {on }}(\mathrm{mA})$ & 173 & 176 & 173 & 177 \\
\cline { 2 - 6 } & $e_{n}(\%)$ & 1.00 & -0.72 & 1.00 & -1.29 \\
\hline \multirow{2}{*}{$25 \%$} & $I_{\text {on }}(\mathrm{mA})$ & 86.1 & 88.0 & 85.6 & 90.2 \\
\cline { 2 - 6 } & $e_{n}(\%)$ & 1.57 & -0.6 & 2.14 & -3.12 \\
\hline
\end{tabular}

Therefore, it can be known that from Table 5, the absolute error percentage is below $1.3 \%$ except for $25 \%$ load. As for $25 \%$ load, the maximum absolute error percentage is $3.12 \%$ and this is because the LED driver operates in DCM.

\subsection{Discussion on Unequal Numbers of LEDs for Four Outputs}

Figures 30-33 are simulations of the unequal LED loads of the four outputs. Only the number of LEDs on $L S_{2}$ and $L S_{4}$ is reduced by two, and the component specifications in the circuit remain unchanged. By the way, the simulation software is called PSIM, made by Powersim, Inc., Rockville, MD, USA.

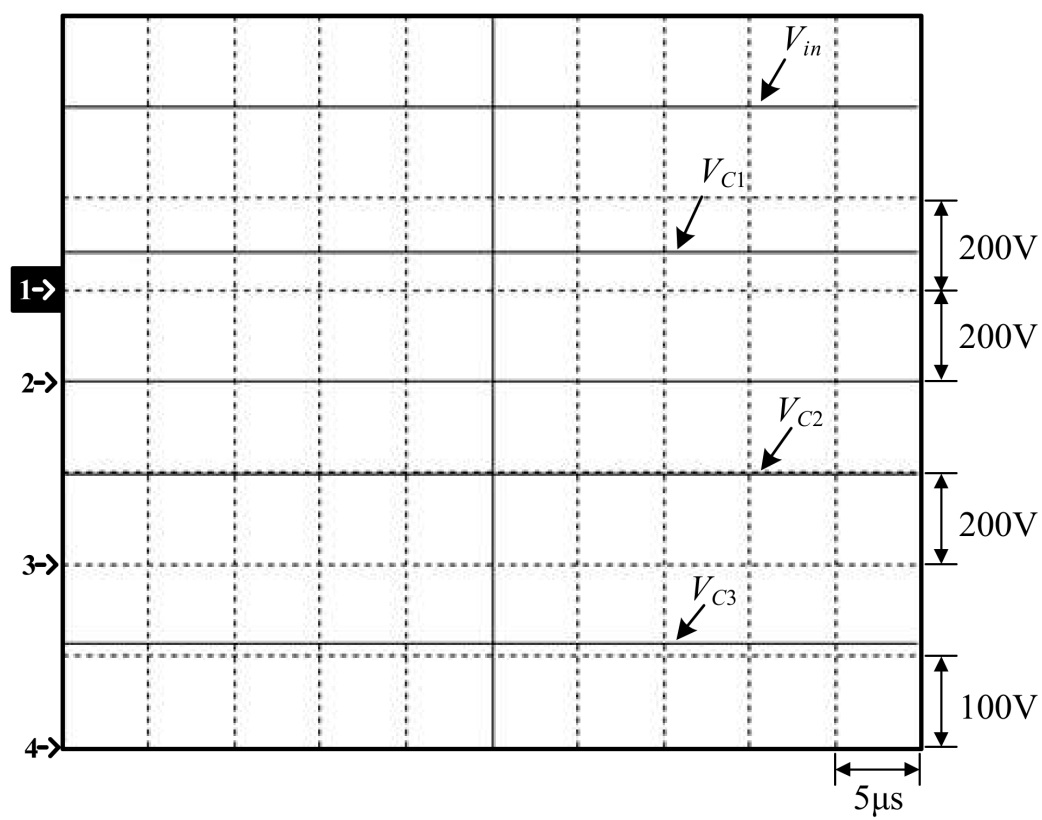

Figure 30. Simulated waveforms relevant to different numbers of LEDs for LED strings: (1) $V_{\text {in }}$; (2) $V_{C 1} ;(3) V_{C 2} ;(4) V_{C 3}$. 


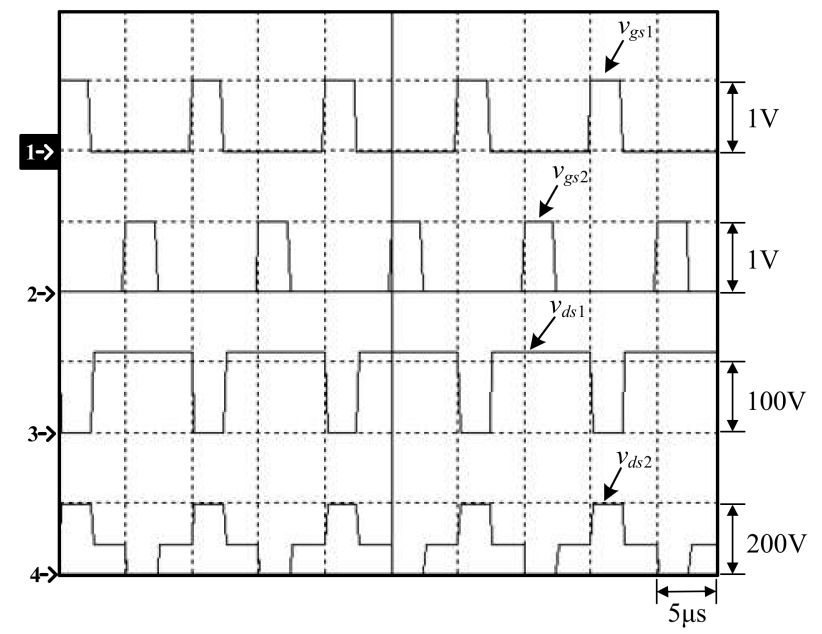

Figure 31. Simulated waveforms relevant to different numbers of LEDs for LED strings: (1) $v_{g s}$; (2) $v_{g s 2} ;(3) v_{d s 1} ;$ (4) $v_{d s 2}$.

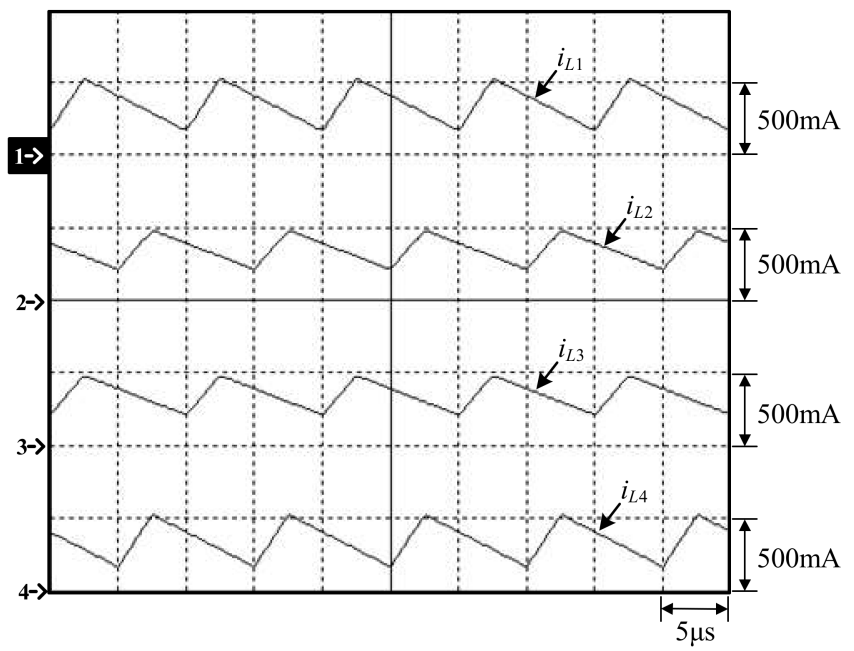

Figure 32. Simulated waveforms relevant to different numbers of LEDs for LED strings: (1) $i_{L 1}$; (2) $i_{L 2} ;(3) i_{L 3} ;(4) i_{L 4}$.

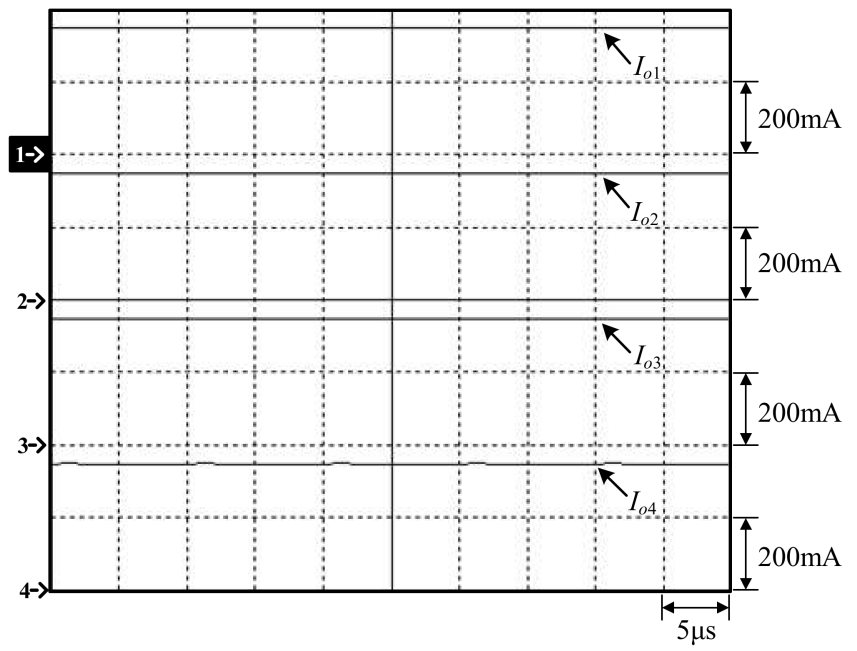

Figure 33. Simulated waveforms relevant to different numbers of LEDs for LED strings: (1) $I_{01}$; (2) $I_{02}$; (3) $I_{03}$; (4) $I_{04}$. 
It can be seen that from Figure 30, in the case of unequal loads, the difference in voltage between different loads will appear on the energy-transferring capacitor, which in turn affects the voltages across the switches, as shown in Figure 31. Because the voltage of the energy-transferring capacitor and the output voltage change, the slopes of magnetization and demagnetization on the inductor currents will also change, as shown in Figure 32. It can be seen from Figure 33 that the different numbers of LEDs on the loads do not affect the characteristics of the capacitor current sharing, and the currents between the four-phase outputs can still achieve automatic current sharing.

\subsection{Efficiency Measurement}

The method for efficiency measurement is shown in Figure 34. First, use a digital meter (Fluke 179) to measure the input voltage and current, and output voltage and current, so that the input power and output power can be obtained. Eventually, the efficiency can be figured out with the obtained input and output power, as shown in Figure 35. From Figure 35 , the efficiency is above $85 \%$ all over the load current rage and the maximum efficiency is about $90.8 \%$.

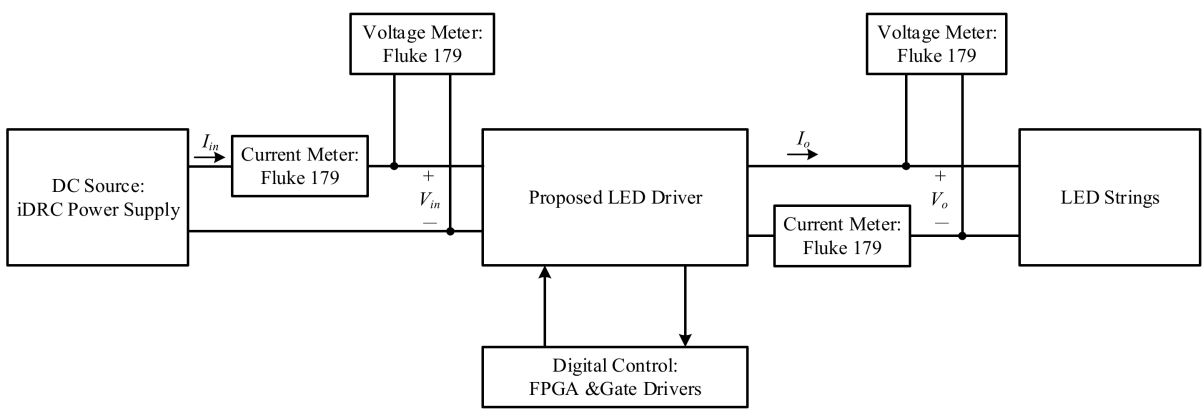

Figure 34. Block diagram of efficiency measurement.

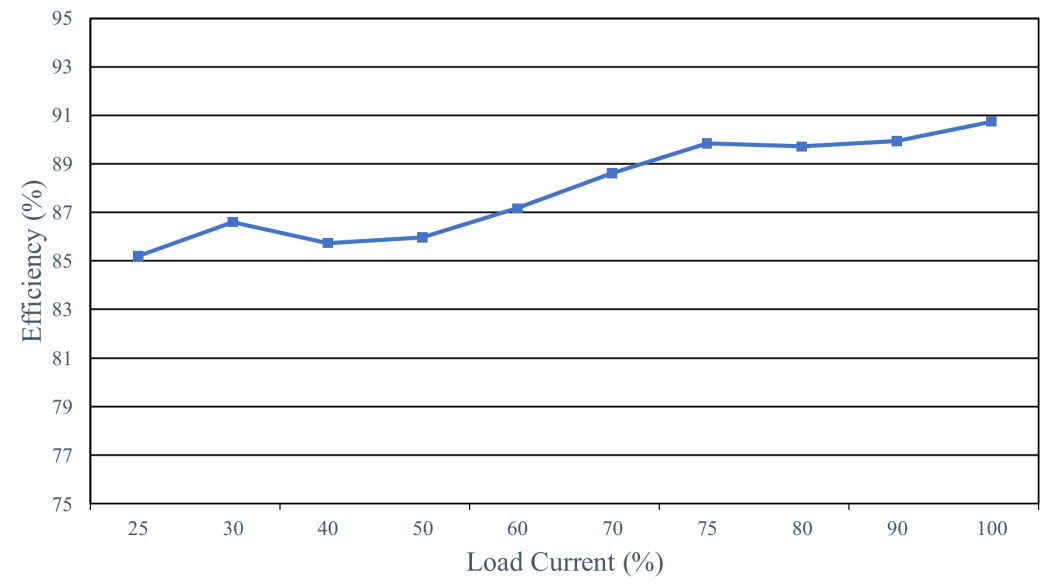

Figure 35. Curve of efficiency versus load current.

\subsection{Comparison}

The circuits in [11-15], with capacitive current balance, are chosen for comparison. In Table 6, the comparison items contain converter type, output count, component count, structure extension, regenerative snubber, switching frequency, resonance, isolation, input voltage, output voltage, and maximum efficiency. From this table, it can be seen that the proposed LED has high step-down voltage gain from $400 \mathrm{~V}$ to $27.6 \mathrm{~V}$. 
Table 6. Circuit comparison between the existing [11-15] and the proposed.

\begin{tabular}{|c|c|c|c|c|c|c|}
\hline Iterm & [11] & [12] & [13] & [14] & [15] & Proposed \\
\hline Converter type & Step-up & Step-up & Step-up & Step-down & Step-down & Step-down \\
\hline Output count & 2 & 2 & 3 & 2 & 6 & 4 \\
\hline $\begin{array}{l}\text { Component } \\
\text { count }\end{array}$ & $\begin{array}{c}\text { Switch } \times 1 \\
\text { Diode } \times 2 \\
\text { Capacitor } \times 4 \\
\text { Transformer } \times 1\end{array}$ & $\begin{array}{c}\text { Switch } \times 1 \\
\text { Diode } \times 3 \\
\text { Capacitor } 4 \\
\text { Coupled Inductor } \times\end{array}$ & $\begin{array}{c}\text { Switch } \times 1 \\
\text { Diode } \times 3 \\
\text { Capacitor } \times 5 \\
1 \text { Inductor } \times 2\end{array}$ & $\begin{array}{c}\text { Switch } \times 4 \\
\text { Diode } \times 2 \\
\text { Capacitor } \times 5 \\
\text { Inductor } \times 1\end{array}$ & $\begin{array}{c}\text { Switch } \times 2 \\
\text { Diode } \times 6 \\
\text { Capacitor } \times 11 \\
\text { Inductor } \times 3\end{array}$ & $\begin{array}{c}\text { Switch } \times 4 \\
\text { Diode } \times 4 \\
\text { Capacitor } \times 7 \\
\text { Inductor } \times 4\end{array}$ \\
\hline $\begin{array}{l}\text { Structure } \\
\text { extension }\end{array}$ & Yes & No & Yes & Yes & Yes & Yes \\
\hline $\begin{array}{l}\text { Regenerative } \\
\text { snubber }\end{array}$ & No & Yes & No & No & No & No \\
\hline $\begin{array}{l}\text { Switching } \\
\text { frequency }\end{array}$ & $100 \mathrm{kHz}$ & $100 \mathrm{kHz}$ & $300 \mathrm{kHz}$ & $65 \mathrm{kHz}$ & $77 \mathrm{kHz}$ & $100 \mathrm{kHz}$ \\
\hline Resonance & No & No & Yes & Yes & Yes & No \\
\hline Isolation & Yes & No & No & No & No & No \\
\hline Input voltage & $12 \mathrm{~V}$ & $3.3 \mathrm{~V}$ & $19 \mathrm{~V}$ & $100 \mathrm{~V}$ & $100 \mathrm{~V}$ & $400 \mathrm{~V}$ \\
\hline Output voltage & $17.3 \mathrm{~V}$ & $17.5 \mathrm{~V}$ & $29.7 \mathrm{~V}$ & $25 \mathrm{~V}$ & $49.2 \mathrm{~V}$ & $27.6 \mathrm{~V}$ \\
\hline $\begin{array}{l}\text { Maximum } \\
\text { efficiency }\end{array}$ & $98.8 \%$ & $92.8 \%$ & $91.9 \%$ & $92.6 \%$ & $93.5 \%$ & $90.8 \%$ \\
\hline
\end{tabular}

\subsection{Loss Breakdown Analysis}

The loss analysis will be performed at room temperature and the proposed circuit is operated at rated load, without considering the copper loss under the skin effect, the line loss of the circuit layout, and the additional switching loss caused by the voltage spike on the switch. At the same time, the power loss of each component is estimated by its specifications. For analysis convenience, it is assumed that the four channels are identical except for four inductor resistances, and hence only the components in the first channel will be considered. Prior to estimating component losses, some currents such as $I_{L 1, \max }$, $I_{L 1, r m s}, I_{d s 1, m a x}, I_{d s 1, r m s}, I_{C 1, r m s}, I_{C o 1, r m s}$, to be shown below:

$$
I_{L 1, \max }=I_{L 1}+0.5 \times \Delta i_{L 1} \Rightarrow I_{L 1, \max }=0.35+0.5 \times 0.34=0.52 \mathrm{~A}
$$

$$
\begin{gathered}
I_{L 1, r m s}=\left[I_{L 1}^{2}+\left(0.5 \times \Delta i_{L 1}\right)^{2} / 3\right]^{1 / 2} \Rightarrow I_{L 1, r m s}=\left[0.35^{2}+(0.5 \times 0.34)^{2} / 3\right]^{1 / 2}=0.364 \mathrm{~A} \\
I_{d s 1, \max }=I_{L 1, \max } \Rightarrow I_{d s 1, m a x}=0.52 \mathrm{~A} \\
I_{d s 1, r m s}=\sqrt{D} \times I_{L 1, r m s} \Rightarrow I_{d s 1, r m s}=\sqrt{0.276} \times 0.364=0.191 \mathrm{~A} \\
I_{C 1, r m s}=\sqrt{2} \times I_{d s 1, r m s}=\sqrt{2} \times 0.191=0.27 \mathrm{~A} \\
I_{C o 1, r m s}=\Delta i_{L 1, r m s}=0.5 \times \Delta i_{L 1} / \sqrt{3}=0.5 \times 0.34 / \sqrt{3}=0.098 \mathrm{~A}
\end{gathered}
$$

where $I_{L 1, \max }$ and $I_{d s 1, \max }$ are the maximum currents in $L_{1}$ and $S_{1}$, respectively, $I_{L 1, r m s}$, $I_{d s 1, r m s}, I_{C 1, r m s}$ and $I_{C o 1, r m s}$ are the rms currents of $L_{1}, S_{1}, C_{1}$ and $C_{0}$, respectively, and $\Delta i_{L 1, r m s}$ is the rms value of the current ripple of $L_{1}$.

Based on (60), the current ripple factor, obtained by $\Delta i_{L 1, r m s}$ divided by $I_{L}$, is $0.098 / 0.52$, equal to 0.28 .

\subsubsection{Loss of Switches $\mathrm{S}_{1}, \mathrm{~S}_{2}, \mathrm{~S}_{3}, \mathrm{~S}_{4}$}

$P_{\text {on, cond }}$ is the switch conduction loss, $P_{\text {turn-on }}$ is the switch conduction switching loss, $P_{\text {turn-off }}$ is the turn-off switching loss, $P_{\text {discharge }}$ is the output charge loss, $P_{g, d r i}$ is the drive 
loss, and $V_{d s}$ is the voltage on the switch when the switch is off. $I_{d s, \text { max }}$ is the maximum current when the switch is on, $C_{o s s}$ is the output capacitance of the switch, $Q_{g \text {-total }}$ is the total charge of the gate, $R_{d s, o n}$ is the resistance when the switch is fully on, $t_{r}$ is the rise time when the switch is on, and $t_{f}$ is the fall time when the switch is off. According to the datasheet of SPA20N60C3, it can be known that $R_{d s, o n}$ is $600 \mathrm{~m} \Omega, C_{o s s}$ is $260 \mathrm{pF}, Q_{g \text {-total }}$ is $87 \mathrm{nC}, t_{r}$ is $5 \mathrm{~ns}$, and $t_{f}$ is $4.5 \mathrm{~ns}$.

$$
\begin{aligned}
& P_{S, \text { loss }}=P_{\text {on, cond }}+P_{\text {turn }- \text { on }}+P_{\text {turn }- \text { off }}+P_{\text {discharge }}+P_{g, d r i} \\
&=I_{d s, \text { rms }}^{2} \times R_{d s, \text { on }}+\left(\frac{V_{d s} \times I_{d s, \text { max }} \times t_{r} \times f_{s}}{6}\right) \\
&+\left(\frac{V_{d s} \times I_{d s, \text { max }} \times t_{f} \times f_{s}}{6}\right)+\frac{4}{3}\left(C_{\text {oss }} \times V_{d s}^{2} \times f_{s}\right) \\
&+\left(Q_{g-\text { total }} \times V_{g s} \times f_{s}\right) \\
& P_{S 1, \text { Loss }}= 0.191^{2} \times 0.6+\frac{100 \times 0.52 \times 5 \mathrm{n} \times 100 \mathrm{k}}{6}+\frac{100 \times 0.52 \times 4.5 \mathrm{n} \times 100 \mathrm{k}}{6} \\
&+ \frac{4}{3}\left(260 \mathrm{p} \times 100^{2} \times 100 \mathrm{k}\right)+(87 \mathrm{n} \times 15 \times 100 \mathrm{k}) \\
&= 0.506 \mathrm{~W} \\
& P_{S, \text { Loss, Total }}=P_{S 1, \text { Loss }}+P_{S 2, \text { Loss }}+P_{S 3, \text { Loss }}+P_{S 4, \text { Loss }} \\
&=0.506+0.506+0.506+0.506=2.024 \mathrm{~W}
\end{aligned}
$$

\subsubsection{Loss of Diodes $\mathrm{D}_{1}, \mathrm{D}_{2}, \mathrm{D}_{3}, \mathrm{D}_{4}$}

$I_{D}$ is the rated-load current flowing through the diode, $V_{F}$ is the forward voltage of the diode, $V_{D}$ is the voltage across the diode when the diode is off, $I_{R}$ is the maximum value of the reverse recovery current, and $t_{r r}$ is the time for the reverse recovery current. $f_{S}$ is the switching frequency. According to the datasheet of DSEP8-02A, $t_{r r}$ is $25 \mathrm{~ns}$, and $V_{F}$ is measured to be $0.45 \mathrm{~V}$.

$$
\begin{gathered}
P_{D, \text { Loss }}=I_{D} \times V_{F}+\frac{1}{2} \times V_{D} \times I_{R} \times T_{r r} \times f_{s} \\
P_{D 1, \text { Loss }}=0.35 \times 0.45+\frac{1}{2} \times 100 \times 50 \mu \times 25 \mathrm{n} \times 100 \mathrm{k} \\
=0.158 \mathrm{~W} \\
P_{D, \text { Loss,Total }}=P_{D 1, \text { Loss }}+P_{D 2, \text { Loss }}+P_{D 3, \text { Loss }}+P_{D 4, \text { Loss }} \\
=0.158+0.158+0.158+0.158=0.632 \mathrm{~W}
\end{gathered}
$$

4.6.3. Loss of Inductances $\mathrm{L}_{1}, \mathrm{~L}_{2}, \mathrm{~L}_{3}$ and $\mathrm{L}_{4}$ Copper Loss

$$
\begin{aligned}
& P_{L 1, \text { Loss }}=I_{L 1, r m s}^{2} \times R_{L 1}=0.364^{2} \times 45.13 \mathrm{~m}=6.41 \mathrm{~mW} \\
& P_{L 2, \text { Loss }}=I_{L 2, r m s}^{2} \times R_{L 2}=0.364^{2} \times 39.99 \mathrm{~m}=5.68 \mathrm{~mW} \\
& P_{L 3, \text { Loss }}=I_{L 3, r m s}^{2} \times R_{L 3}=0.364^{2} \times 37.12 \mathrm{~m}=5.28 \mathrm{~mW} \\
& P_{L 4, \text { Loss }}=I_{L 4, r m s}^{2} \times R_{L 4}=0.364^{2} \times 43.61 \mathrm{~m}=6.20 \mathrm{~mW}
\end{aligned}
$$

Iron Loss

$$
\begin{aligned}
B_{m 1} & =\frac{\Delta B_{1}}{2}=\frac{L_{1} \times I_{L 1, \max }}{2 \times N \times A_{e}} \\
& =\frac{600 \times 10^{-6} \times 0.52}{2 \times 17 \times 0.62} \times 10^{8} \\
& =148 \mathrm{mT}
\end{aligned}
$$




$$
\begin{aligned}
P_{f e 1} & =0.15 \mathrm{~W} / \mathrm{cm}^{3} \times V_{e} \\
& =0.15 \mathrm{~W} / \mathrm{cm}^{3} \times 2.79 \mathrm{~cm}^{3} \\
& =0.419 \mathrm{~W}
\end{aligned}
$$

where $R_{L 1}, R_{L 2}, R_{L 3}$ and $R_{L 4}$ are the resistance values of inductors $L_{1}, L_{2}, L_{3}$ and $L_{4}$, respectively. According to the core specification table of Ferrite MB4, the core of this material will have a loss of $0.15 \mathrm{~W} / \mathrm{cm}^{3}$ at $B_{m 1}=148 \mathrm{mT}$. Multiplying this loss by the effective core volume $V_{e}$ yields the estimated core loss.

Eventually, adding the results of (67), (68), (69), (70), and (72) yields the power loss of the inductors:

$$
\begin{aligned}
P_{L, \text { Loss }, \text { Total }} & =P_{\text {L1,Loss }}+P_{L 2, \text { Loss }}+P_{L 3, \text { Loss }}+P_{L 4, \text { Loss }}+P_{f e 1} \times 4 \\
& =6.41 \mathrm{~m}+5.68 \mathrm{~m}+5.28 \mathrm{~m}+6.20 \mathrm{~m}+0.419 \times 4 \\
& =1.7 \mathrm{~W}
\end{aligned}
$$

4.6.4. Loss of Capacitors $C_{1}, C_{2}, C_{3}$ and $C_{o}$

The resistors $R_{C 1}, R_{\mathrm{C} 2}, R_{\mathrm{C} 3}$ and $R_{\mathrm{Co}}$ are the equivalent series resistance (ESR) measured by the capacitors $C_{1}, C_{2}, C_{3}, C_{4}, C_{5}$ and $C_{0}$ at $100 \mathrm{kHz}$, respectively.

$$
\begin{aligned}
P_{C 1, \text { Loss }} & =I_{C 1, \text { rms }}^{2} \times R_{C 1}=0.27^{2} \times 0.5=30.5 \mathrm{~mW} \\
P_{C 2, \text { Loss }} & =I_{C 2, \text { rms }}^{2} \times R_{C 2}=0.27^{2} \times 0.5=30.5 \mathrm{~mW} \\
P_{C 3, \text { Loss }} & =I_{C 3, \text { rms }}^{2} \times R_{C 3}=0.27^{2} \times 0.5=30.5 \mathrm{~mW} \\
P_{\text {Co1,Loss }}= & I_{\text {Co1,rms }}^{2} \times R_{C o 1}=0.098^{2} \times 45 \mathrm{~m}=0.87 \mathrm{~mW} \\
P_{C, \text { Loss }, \text { Total }} & =P_{C 1, \text { Loss }}+P_{C 2, \text { Loss }}+P_{C 3, \text { Loss }}+P_{\text {Co1,Loss }} \times 4 \\
& =30.5 \mathrm{~m}+30.5 \mathrm{~m}+30.5 \mathrm{~m}+0.87 \mathrm{~m} \times 4 \\
& =94.98 \mathrm{~mW}
\end{aligned}
$$

After adding the results of (63), (66), (73), and (78), the estimated total loss is

$$
\begin{aligned}
P_{\text {Loss }, \text { Total }} & =P_{S, \text { Loss,Total }}+P_{D, \text { Loss, Total }}+P_{L, \text { Loss,Total }}+P_{C, \text { Loss, Total }} \\
& =2.024+0.632+1.7+0.095 \\
& =4.44 \mathrm{~W}
\end{aligned}
$$

According to the calculation result of (79), it can be known that the conversion efficiency at rated load is:

$$
\begin{aligned}
\eta & =\frac{P_{o, \text { rated }}}{P_{0, \text { rated }}+P_{\text {Loss }, \text { Total }}} \\
& =\frac{38.64}{38.64+4.44} \times 100 \%=89.69 \%
\end{aligned}
$$

From the result of (80), the estimated efficiency of the proposed circuit at rated load is $89.69 \%$, which is about $1.1 \%$ different from the actual measured value of $90.8 \%$. The reason is that the measurement environment of the relevant parameters on the datasheet of each component is different from that due to the mentioned LED driver. For example, the measurement environment for switches to measure $t_{r}$ and $t_{f}$ is under the condition that $v_{d s, o f f}=380 \mathrm{~V}$ and $i_{d s, a v g}=7.3 \mathrm{~A}$, but the actual circuit parameters are $v_{d s, o f f}=200 \mathrm{~V}$, $i_{d s, a v g}=0.35 \mathrm{~A}$, so the estimated efficiency is lower than the actual efficiency. Figure 36 shows the estimated power loss distribution percentage. It can be seen from this figure that the power loss caused by the inductance and switches has the greatest impact on the overall efficiency. If a wire diameter with a lower resistance value or an active switch with better features can be selected, then the efficiency of the circuit can be improved further. 


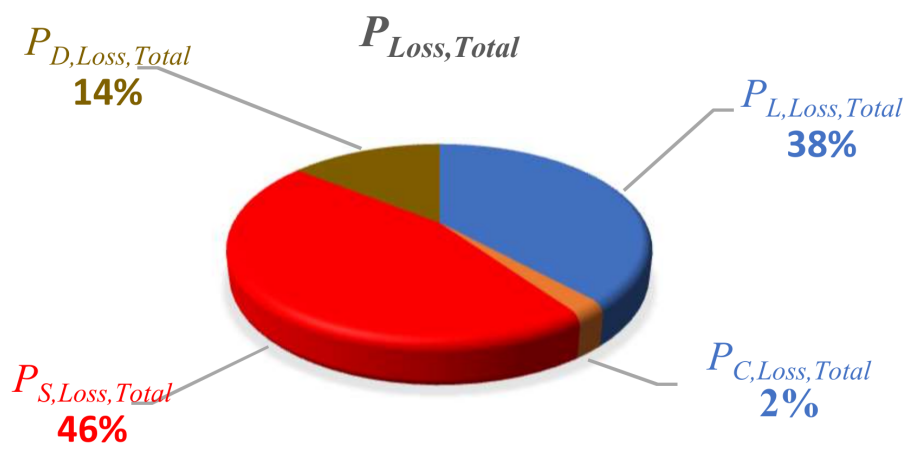

Figure 36. Loss breakdown analysis.

\section{Conclusions}

The proposed LED driver has several merits as following:

(1) This LED driver inherently possesses automatic current sharing and high step-down voltage gain.

(2) This circuit is of SIMO and structure extension, and under automatic current sharing, the number of LED strings for each output can be different.

(3) As compared with the traditional four-phase interleaved buck converter under automatic current sharing, the maximum duty cycle of the proposed circuit is relatively large and not changed for structure extension whereas the maximum duty cycle of the traditional circuit will be reduced as the number of outputs is increased.

(4) As compared with automatic current sharing by using the differential-mode transformer, the proposed circuit has no magnetic resetting loop required.

(5) The efficiency is above $85 \%$ over all the load current and the maximum efficiency is about $90.8 \%$.

By the way, in the future, the soft switching technique will be applied to this circuit to improve the efficiency further.

Author Contributions: Conceptualization, Y.-T.Y. and K.-I.H.; methodology, Y.-T.Y.; software, Y.-D.T.; validation, Y.-T.Y., K.-I.H. and Y.-D.T.; formal analysis, Y.-T.Y.; investigation, Y.-D.T.; resources, Y.-T.Y.; data curation, Y.-D.T.; writing-original draft preparation, K.-I.H.; writing-review and editing, K.-I.H.; visualization, Y.-T.Y.; supervision, K.-I.H.; project administration, K.-I.H.; funding acquisition, K.-I.H. All authors have read and agreed to the published version of the manuscript.

Funding: This research was funded by the Ministry of Science and Technology, Taiwan, under the Grant Number: MOST 110-2221-E-027-045-MY2.

Institutional Review Board Statement: Not applicable.

Informed Consent Statement: Not applicable.

Data Availability Statement: No new data were created or analyzed in this study. Data sharing is not applicable to this article.

Conflicts of Interest: The authors declare no conflict of interest.

\section{References}

1. Yu, W.; Lai, J.S.; Ma, H.; Zheng, C. High-efficiency DC-DC converter with twin bus for dimmable LED lighting. IEEE Trans. Power Electron. 2011, 26, 2095-2100. [CrossRef]

2. Jiang, W.-Z.; Hwu, K.-I.; Shieh, J.-J. LLC LED driver with current-sharing capacitor having low voltage stress. Energies. 2021, 14, 112. [CrossRef]

3. Zhang, Y.; Rong, G.; Qu, S.; Song, Q.; Tang, X.; Zhang, Y. A high-power LED driver based on single inductor-multiple output DC-DC converter with high dimming frequency and wide dimming range. IEEE Trans. Power Electron. 2020, 35, 8501-8511. [CrossRef] 
4. Sun, J.; Tang, X.; Xing, Y.; Chen, B.; Wu, H.; Sun, K. Current sharing control of interleaved LLC resonant converter with hybrid rectifier. In Proceedings of the Applied Power Electronics Conference and Exposition, Anaheim, CA, USA, 17-21 March 2019; pp. 2223-2227.

5. Mazelan, F.-N.; Kannan, R.; Hasan, K.N.-M.; Ali, A. Multi-input power converter for renewable energy sources using active current sharing schemes. In Proceedings of the IEEE Student Conference on Research and Development, Bandar Seri Iskandar, Malaysia, 15-17 October 2019; pp. 275-279.

6. Yau, Y.T.; Hwu, K.I.; Shieh, J.J. Minimization of output voltage ripple of two-phase interleaved buck converter with active clamp. Energies 2021, 14, 5215. [CrossRef]

7. Martins, M.; Perdigao, M.S.; Mendes, A.M.S.; Pinto, R.A.; Alonso, J.M. Analysis, design, and experimentation of a dimmable resonant-switched-capacitor LED driver with variable inductor control. IEEE Trans. Power Electron. 2017, 32, 3051-3062. [CrossRef]

8. Hwu, K.-I.; Tu, W.-C.; Hong, M.-J. A dimmable LED driver based on current balancing transformer with magnetizing energy recycling considered. IEEE J. Disp. Technol. 2014, 10, 388-395. [CrossRef]

9. Lin, Y.L.; Chiu, H.J.; Lo, Y.K.; Leng, C.M. Light-emitting diode driver with a combined energy transfer inductor for current balancing control. IET Power Electron. 2015, 8, 1834-1843. [CrossRef]

10. Jiang, W.-Z.; Hwu, K.-I.; Chen, H.-H. Applying hybric passive current-sharing components to non-isolated LED driver. In Proceedings of the International Symposium on Computer, Consumer and Control, Taichung City, Taiwan, 13-16 November 2020; pp. 259-262.

11. Hwu, K.-I.; Jiang, W.-Z. Expendable two-channel LED driver with galvanic isolation and automatic current balance. IET Power Electron. 2018, 11, 825-833. [CrossRef]

12. Hwu, K.-I.; Jiang, W.-Z. Single-switch coupled-inductor-based two-channel LED driver with a passive regenerative snubber. IEEE Trans. Power Electron. 2017, 32, 4482-4490. [CrossRef]

13. Liu, X.; Zhou, Q.; Xu, J.; Lei, Y.; Wang, P.; Zhu, Y. High-efficiency resonant LED backlight driver with passive current balancing and dimming. IEEE Trans. Ind. Electron. 2018, 65, 5476-5486. [CrossRef]

14. Zhang, X.; Cai, H.; Guan, Y.; Han, S.; Wang, Y.; Dalla Costa, M.A.; Alonso, J.M.; Xu, D. A soft-switching transformer-less step-down converter based on resonant current balance module. IEEE Trans. Power Electron. 2021, 36, 8206-8218. [CrossRef]

15. Gucin, T.N.; Fincan, B.; Biberoglu, M. A series resonant converter-based multichannel LED inherent current balancing and dimming capability. IEEE Trans. Ind. Electron. 2019, 34, 2693-2703. [CrossRef]

16. Chuang, C.F.; Pan, C.T.; Cheng, H.C. A novel transformer-less interleaved four-phase step-down DC converter with low switch voltage stress and automatic uniform current-sharing characteristics. IEEE Trans. Power Electron. 2016, 31, 406-441. [CrossRef]

17. Hwu, K.-I.; Jiang, W.-Z.; Wu, P.-Y. An expandable four-phase interleaved high step-down converter with low switch voltage stress and automatic uniform current sharing. IEEE Trans. Ind. Electron. 2016, 63, 6064-6072. [CrossRef]

18. Hwu, K.-I.; Yau, Y.-T. Performance enhancement of boost converter based on PID controller plus linear-to-nonlinear translator. IEEE Trans. Power Electron. 2010, 25, 1351-1361. [CrossRef] 